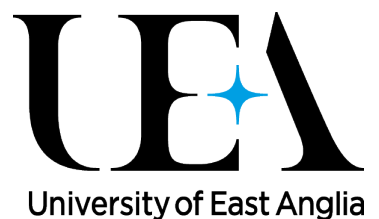

\title{
Platform competition in the tablet PC market: The effect of application quality
}

\author{
Thanh Doan \\ Centre for Competition Policy \& School of Economics \\ University of East Anglia \\ Fabio Maria Manenti \\ Department of Economics and Management, University of Padua \\ Franco Mariuzzo \\ Centre for Competition Policy \& School of Economics \\ University of East Anglia

\section{CCP Working Paper 20-08} \\ This version: December 2020 \\ Apple iOS is a closed platform; Google Android is open. In this paper, we \\ combine data on iOS and Android tablet sales with data on the top 1000 \\ mobile applications from both platforms for five European countries and \\ estimate a structural demand model. We find that the quality of \\ applications affects tablet demand. We then run two counterfactuals. In \\ line with our theory, the exclusion of low-quality applications is beneficial \\ to tablet producers in both platforms but is more pronounced for Apple. \\ Tablet producers in the platform with lower quality applications gain most \\ from cross-platform app interoperability.
}

\section{Contact Details:}

Franco Mariuzzo f.mariuzzo@uea.ac.uk 


\section{Highlights}

\section{Platform competition in the tablet PC market: The effect of application quality**}

Thanh Doan,Fabio Maria Manenti,Franco Mariuzzo

- We study the effect of application quality on tablet demand based on three waves of tablet data and data on top 1000 applications in both iOS and Android stores for five European countries.

- We sketch a theory of asymmetric platform competition and conduct a structural demand estimation aimed at examining the impact of application quality on tablet demand.

- Application quality has a significant positive impact on tablet demand.

- The result of our first counterfactual is that the exclusion of low-quality apps leads to the gain in terms of market share and profit for both iOS and Android tablets, but the gain is larger for iOS.

- The result of our second counterfactual is that cross-platform interoperability generates higher market shares and profits for tablets in the platform with lower average application quality.

**We would like to thank Steve Davies, Farasat Bokhari, Michael Kummer, Luis Aguiar, our audiences at Centre for Competition Policy seminar, IBEO 2019 workshop, EARIE 2019 conference, and XXXIV Jornadas de Economía Industrial for useful comments and discussions 


\title{
Platform competition in the tablet PC market: The effect of application quality**
}

\author{
Thanh Doan $^{a, b, *, 1}$, Fabio Maria Manenti ${ }^{c}$ and Franco Mariuzzo ${ }^{a, b, 1}$ \\ ${ }^{a}$ School of Economics, University of East Anglia \\ ${ }^{b}$ Centre for Competition Policy, University of East Anglia \\ ${ }^{c}$ Department of Economics and Management “M. Fanno”, University of Padua
}

\section{ARTICLE INFO}

\section{Keywords:}

Android

indirect quality effect

iOS

mobile application

tablet demand.

\begin{abstract}
A B S TR ACT
Apple iOS is a closed platform; Google Android is open. In this paper, we combine data on iOS and Android tablet sales with data on the top 1000 mobile applications from both platforms for five European countries and estimate a structural demand model. We find that the quality of applications affects tablet demand. We then run two counterfactuals. In line with our theory, the exclusion of low-quality applications is beneficial to tablet producers in both platforms but is more pronounced for Apple. Tablet producers in the platform with lower quality applications gain most from cross-platform app interoperability.
\end{abstract}

JEL classifiers: L13, L15, L51, L63

\section{Introduction}

The introduction of digital distribution platforms for mobile operating systems developed by Apple and Google in 2008 has marked an important milestone for the booming of mobile platforms. Since its launch, the number of mobile applications (apps) has grown exponentially, counting by the end of August 2020, about 2.8 million apps in Google Play and nearly 2 million in Apple App Store, ${ }^{1}$ the two largest app stores by far. Taking advantage of the growing app industry, a new generation of hardware - tablet PC - was introduced into the market. Apple delivered its first generation of iPad device in early 2010 , followed closely by several other manufacturers.

It is commonly recognized that the wide availability of applications represents one of the explanations for the growth in the demand for tablets; nonetheless, an empirical evaluation of the exact role of apps in the tablet market is still missing. Filling this gap appears to be particularly interesting, also in light of the specific characteristics of the tablet market, tightly dominated by two alternative platforms: the iOS-based and the Android-based platforms. Of interest in our paper, these platforms follow two different business models and represent most of the market. The iOS-based platform is vertically integrated by Apple, which both controls the production of devices and manages the dedicated app store (App Store). The Android-based platform is open, with competitive and independent manufacturers producing the devices and Google managing the app store (Google Play).

** We would like to thank Steve Davies, Farasat Bokhari, Michael Kummer, Luis Aguiar, our audiences at Centre for Competition Policy seminar, IBEO 2019 workshop, EARIE 2019 conference, and XXXIV Jornadas de Economía Industrial for useful comments and discussions

*Corresponding author

@ duc.doan@uea.ac.uk (T. Doan)

$\operatorname{ORCID}(\mathrm{s})$ :

${ }^{1}$ Source: Statista.com. 
We study how the quality of the apps distributed in each dedicated app store affects the outcome of the tablet market; in particular, we focus on the differentiated effects of the quality of the apps in the two stores on the competition between the iOS-based and the Android-based tablets.

Since the seminal papers by Katz and Shapiro [1986] and Church and Gandal [1992], a rich body of literature has discussed the role of the so-called indirect network effects arising when the benefit from using a product increases with the variety of complementary goods that are compatible. In hardware markets, it has been proved that by favoring the production of a large variety of compatible software, hardware firms can earn a strategic advantage needed to gain and preserve market dominance. In the case of tablets, the variety of applications available in the two main stores is so wide and extensive that there is little point in estimating the effect of increasing the number of apps in tablet adoption as this effect would be potentially negligible. For this reason, rather than the number of applications, we focus on the effect generated by the quality of the apps, proxied using customer ratings, available in the two stores.

We first introduce a simple theoretical analysis aimed at representing the impact of apps quality in the strategic interactions among two incompatible platforms. Platform competition is modelled using a classic Hotelling framework, where platforms are both horizontally and vertically differentiated-vertical differentiation accrues both from tablet characteristics and, important for our scope, from the quality of the apps available in the stores of the two platforms. We model a two-stage game, where consumers first select the platform and then, given their choice, their most preferred tablet model. Consumer preferences for tablets are affected by the quality of the applications available for that platform. The theoretical model allows us to derive a series of testable predictions. We then construct an econometric model relying on the discrete choice literature for product differentiation; in line with our two-stage theoretical framework, we choose the random coefficient nested logit model proposed by Grigolon and Verboven [2014], where the nest captures the heterogeneity in operating systems. We augment their model with observable consumer demographics, as in Nevo [2001]. This allows us to estimate richer own-price and cross-price elasticities of demand for both Apple and Android tablets and related these to profitability and welfare.

Estimations are based on a sample made of three waves of product-level data for tablets and apps distributed in five European countries (Germany, France, Italy, Spain, and the UK) over the period September 2013-February 2014. Consumer demographics are recovered from a Eurostat dataset. In addition to the demand side, we also incorporate the cost functions and derive the pricing equations. This system of simultaneous demand and pricing equations enables us to estimate the primitives on the tablet market and to investigate in detail the role of app quality in the tablet market.

Then, we conduct two counterfactual analyses in which we evaluate how equilibrium prices, market shares, and profits of tablet manufacturers would be if $i$ ) platforms eliminated low-quality applications from their app store, and ii) if a regulator mandates platform's interoperability - a policy that would impose the level of app quality to be the same on both platforms. 
Our findings confirm that app quality has a significant impact on tablet demand. Specifically, and in line with our theoretical model, the results of our first counterfactual suggest that market shares and profits of manufacturers of both platforms would increase if platforms had removed low-quality apps from their stores. Interestingly, our estimations reveal that burying low-quality applications generates larger profits for Apple than for Android tablet producers. According to this result, Apple has more to gain than Android tablet producers from increasing the quality of the apps distributed in the dedicated store. Our evidence provides a possible rationale for why in Apple's App Store, the distribution of apps undergoes a much stricter quality check than in Google Play. ${ }^{2}$ In the second counterfactual, we study the effects of a policy that imposes the two platforms to be interoperable. Interoperability is a characteristic of a product to work with other products or systems without any restrictions. In our context, imposing the two operating systems to be interoperable would imply that all the apps developed for one platform could also run on the other. Consequently, with interoperability, the level of app quality is the same on both platforms. We find that such a policy would favor Android tablet producers. Our data reveal that on Google Play, the average quality of apps, measured based on user ratings, is lower than in App Store; hence a policy that mandates interoperability would increase the average quality of Android apps, pushing the demand in favor of Android tablets. Interestingly, though, we find that forcing interoperability between platforms enhances consumer welfare in the tablet market.

Our paper aims at contributing to the literature analyzing the impact of the quality of complementary products on demand for high-tech products. The literature on complementary products has mainly focused on the role of indirect network effects. However, under the quite natural assumption that in the presence of complementary products of higher quality network effects are stronger, in several papers, the network effects have been estimated by incorporating some measure of the quality of complementary products. An interesting theoretical contribution in this direction is in Viecens [2006]. The author presents a model of competition between two two-sided platforms in which the preferences of the agents on the two sides of the market are influenced not only by the variety of agents on the other side but also by their quality. Similar to our approach, in their paper, the quality is determined by the quality of the type of sellers the platform house, namely the quality of the complementary products. The relevance of the quality of complementary products is also acknowledged in Nair et al. [2004]. The authors want to estimate the effects of the availability of software on demand for personal digital assistants (PDAs), and they recognize that consumers benefits of adopting a given PDA should be related not only to the variety but also to the quality of compatible software; nonetheless, due to data availability, they estimate demand only using an index of software availability based on simple downloads.

On similar lines is the paper by Corts and Lederman [2009], where the authors estimate indirect network effects for the demand of game-consoles. In their model, the source of externalities is software variety and quality. The quality of the software, for a given console, is measured by the number of "hits" (i.e., games reaching certain sales

\footnotetext{
${ }^{2}$ Android producers also have fewer instruments to eliminate bad apps, as they do not manage the app store. See Comino et al. [2018] for a discussion of the different approaches towards quality control between Apple Store and Google Play.
} 
thresholds) available on that platform. In this literature, the paper which is probably closest to ours is Kim et al. [2014]. The authors explicitly argue that if the quality is not taken into account in the estimation, there is a real risk of significantly underestimating the impact of the externalities. In their theoretical framework, based on Church and Gandal [1992], they incorporate the quality dimension into the network externalities by allowing consumers to receive different marginal utilities from complementary products of different quality. The theoretical framework is then applied to the game-console market. In a way, similar to ours, they employ the customers' review score as the measure of game quality.

Previous literature has studied the important role of the platform's governance/regulation in the competition among platforms. Hagiu [2009] examines whether platforms have an incentive to exclude low-quality sellers, which enables them to attract more buyers. He finds that if the buyer's valuation for seller quality is sufficiently high, platforms would be profitable to exclude low-quality sellers. Casadesus-Masanell and Hałaburda [2014] claims that platforms can be beneficial from limiting the number of software, as it would encourage more users using the same software, and thus generates more direct network effects. Although these works have provided theoretical evidence of the benefits when the platform imposes governance rules, there is still a lack of empirical evidence in previous literature. Our first counterfactual, in which we study the impacts of excluding low-quality apps on the tablet market, aims to fill this gap.

Our paper also contributes to the literature on technology compatibility and interoperability. When technologies are perfectly interoperable, users of a given technology can interact with all the other users, independently of the technology they patronize. Typically, firms may benefit from interoperability as it allows users to enjoy a larger network benefit that firms can try to seize via appropriate commercial strategies. At the same time, though, fully interoperable platforms tend to be less differentiated to the detriment of the producers that might compete more aggressively on prices. In our second counterfactual, we discuss the impact of mandating interoperability between Android and iOS platforms. This would mean that all the apps developed for one platform could also run on the other. The compatibility-interoperability problem had been discussed early in the network effects and platforms literature by Katz and Shapiro [1985], Farrell and Saloner [1985], Matutes and Regibeau [1988], Economides [1989], and Katz and Shapiro [1994]. They have studied firms' incentives to produce individual components compatible with components of other manufacturers instead of "systems" made of components that are incompatible with components of competing manufacturers. In our context, characterized by competition between open and closed platforms, we show that interoperability is desirable from the social welfare perspective of the market under study, even though it largely benefits Android-based tablet producers.

The outline of this paper is the following. In the next section, we introduce a simple theoretical model; this analysis will provide some predictions to be tested in the empirical part. The third section develops the econometric model, while Section 4 describes the data and summary statistics. Section 5 presents the estimation strategy and the empirical estimation, along with a discussion of the main results, and Section 6 concludes. 


\section{The theoretical model of platform competition}

We assume the tablet market to be characterized by the presence of two alternative platforms based on incompatible operating systems: iOS, developed and controlled by Apple, and Android, an open-source operating system developed and maintained by Google. Apple sells an iOS-based device, iPad, and competes with $n$ tablet manufacturers of Android-based tablets. Apple and Google control the two app stores, Apple Store and Google Play, respectively, where users can download applications for their devices.

For the reasons that will become clearer below, we assume a two-stage competition process:

$t_{1}$ : in the first stage, consumers decide which platform to adopt (inter-platform competition) and, in the case they chose iOS, they buy iPad;

$t_{2}$ : in the second stage, those who have chosen Android will decide which product to purchase among the $n$ alternatives (intra-platform competition).

For notational convenience, in the remaining, we use the subscripts 1 for the iOS/Apple Store platform and the subscript 2 for the Android/Google Play platform.

The two platforms are differentiated along several dimensions. To mention some of them, Apple's and Androidbased devices have different hardware, different reputation/brand recognition, they are based on two incompatible operating systems and, to a large extent, the two dedicated app stores contain different applications. For these reasons, it is natural to assume the two platforms as both horizontally and vertically differentiated. Formally, we represent interplatform competition using a simple Hotelling line, with qualitatively different products. Regarding the quality of a tablet, we model it as a combination of the quality of its two main components, hardware, and software/applications. More specifically, indicating with $z_{h j}$ the quality of the hardware/recognition of tablets of platform $j$ and with $\bar{z}_{s j}$ the average quality of the apps available in the store of platform $j$, we assume that the overall quality of platform $j$ 's tablets is given by the product $z_{h j} \bar{z}_{s j}$ since there is no quality if either is missing.

We solve the model by backward induction. In the second stage, competition occurs between Android producers. As discussed above, platform 2 tablet producers compete for those users that have chosen to purchase a device of platform 2 in stage one. Let us indicate with $q_{h 2}$ the mass of these customers. For the sake of simplicity, we model intra-platform competition as a Salop oligopoly model with horizontal product differentiation. We assume that the $n$ producers of platform 2 devices are equidistantly located on a unit length circle with customers who are uniformly distributed along the circle. We further simplify our analysis by assuming that in the second stage, platform 2 producers compete by taking the mass of users $q_{h 2}$ as given.

As in a standard Salop circular model, the consumer located in $x$ takes his purchasing decision by solving $\max _{\mu=i, i+1}\left\{z_{h 2} \bar{z}_{s 2}-t\left|d_{\mu}-x\right|-p_{\mu}\right\}$, where firms $\mu=i, i+1$ are the firms between which the consumer is located, 
and where firm $\mu$ 's location is $d_{\mu}=\mu / n$. The parameter $t$ indicates the unit transportation cost measuring the degree of horizontal product differentiation between Android producers. Therefore, the symmetric equilibrium price turns out to be:

$$
p_{h 2}^{*}=c_{2}+\frac{t}{n}
$$

where $c_{2}$ is the common marginal cost of producing a platform 2 tablet.

In stage 1 , consumers observe hardware qualities, $z_{h j}$, and the average qualities of the apps available in the two stores, $\bar{z}_{s j}, j=1,2$. They also observe the price of an iPad, $p_{h 1}$, and can anticipate the equilibrium price of tablets of platform $2, p_{h 2}$. With this information, they decide which platform to adopt.

As said, inter-platform competition occurs a' la Hotelling; platform 1 is located at $l_{1}$ and platform 2 at $l_{2}$, with $1>l_{2}>l_{1}>0$. Consumers between $l_{1}$ and $l_{2}$ compare net utilities and choose. The net utilities of the user located in $x \in\left(l_{1}, l_{2}\right)$ are as follows:

$$
u_{h 1}(x)=z_{h 1} \bar{z}_{s 1}-k\left(x-l_{1}\right)-p_{h 1}, \quad u_{h 2}(x)=z_{h 2} \bar{z}_{s 2}-k\left(l_{2}-x\right)-p_{h 2},
$$

where $x$ is uniformly distributed in $[0,1]$. The parameter $k$ represents the unit transportation cost and indicates the degree of horizontal inter-platform differentiation; the mass of customers is normalized to 1 . Using this setting, in the appendix, we show that the price that platform one charges at the equilibrium and platform quantities correspond to the following:

$$
\begin{aligned}
& p_{h 1}^{*}=\frac{3 c_{1}+c_{2}}{6}+\frac{t+n\left(3 \bar{z}_{s 1} z_{h 1}-\bar{z}_{s 2} z_{h 2}\right)+k n\left(l_{2}-l_{1}\right)}{6 n}, \\
& q_{h 1}^{*}=\frac{l_{2}-l_{1}}{4}+\frac{1}{4} \frac{t}{k n}+\frac{3 \bar{z}_{s 1} z_{h 1}-\bar{z}_{s 2} z_{h 2}-3 c_{1}+c_{2}}{4 k},
\end{aligned}
$$

and

$$
q_{h 2}^{*}=\frac{7\left(l_{2}-l_{1}\right)}{12}-\frac{17}{12} \frac{t}{k n}-\frac{3 \bar{z}_{s 1} z_{h 1}-17 \bar{z}_{s 2} z_{h 2}-3 c_{1}+17 c_{2}}{12 k},
$$

where $c_{1}$ is the marginal cost of producing a platform 1 tablet. 


\subsection{Predictions}

From these expressions, we can derive a series of testable predictions on the characteristics of the equilibrium.

The first prediction regards the effect of a change in the average quality of the apps available on platform $j$. The platform can obtain this result by removing low-quality apps. ${ }^{3}$ From $q_{h 1}^{*}$ and $q_{h 2}^{*}$ it follows immediately that an increase in the quality of the apps available on the dedicated app store of the platform $j$ stimulates the demand for tablets $j$ (ownquality effect), ${ }^{4}$ and reduces the demand for the rival platform (cross-quality effect):

$$
\frac{d q_{h 1}^{*}}{d \bar{z}_{s 1}}=\frac{3}{4} \frac{z_{h 1}}{k}>0, \quad \frac{d q_{h 2}^{*}}{d \bar{z}_{s 2}}=\frac{17}{12} \frac{z_{h 2}}{k}>0,
$$

and

$$
\frac{d q_{h 1}^{*}}{d \bar{z}_{s 2}}=-\frac{1}{4} \frac{z_{h 2}}{k}<0, \quad \frac{d q_{h 2}^{*}}{d \bar{z}_{s 1}}=-\frac{1}{4} \frac{z_{h 1}}{k}<0 .
$$

Note also that, in absolute values, own-quality effects are larger than cross-quality effects.

Expressions (5) reveal another interesting observation. If platform 1 hardware quality/reputation is sufficiently larger than that of platform 2, formally if $z_{h 1}>\frac{17}{9} z_{h 2}$, our model predicts that the impact on demand for an increase in the quality of applications is larger for platform 1 tablets than for platform 2. We cannot test specifically whether this condition on hardware quality is satisfied but, anecdotal evidence suggests that it is as, on average, the quality of Android tablets is commonly recognized as being far lower than that of Apple's ones.

These arguments suggest that manufacturers of both platforms benefit from an increase in the quality of the apps available in their store. We can also use our equilibrium prices and quantities to check which platform benefits more. Expressions (20) and (21) in Appendix A.1 provide the first-stage tablet producers' profit functions, given prices, and app qualities. The quality of the apps on each platform affects profits both directly, via the effect it has on the number of tablets sold, and indirectly, via the change in prices. Totally differentiating the aforementioned profit functions with respect to $\bar{z}_{s i}$, yields:

$$
\begin{aligned}
& \frac{d \pi_{h 1}\left(p_{h 1}\left(\bar{z}_{s 1}\right), p_{h 2}\left(\bar{z}_{s 1}\right), \bar{z}_{s 1}\right)}{d \bar{z}_{s 1}}=\underbrace{\frac{\partial \pi_{h 1}}{\partial p_{h 1}} \frac{d p_{h 1}}{d \bar{z}_{s 1}}}_{(1)}+\underbrace{\frac{\partial \pi_{h 1}}{\partial p_{h 2}} \frac{d p_{h 2}}{d \bar{z}_{s 1}}}_{(2)}+\underbrace{\frac{\partial \pi_{h 1}}{\partial \bar{z}_{s 1}}}_{(3)}, \\
& \frac{d \pi_{h 2}\left(p_{h 1}\left(\bar{z}_{s 2}\right), p_{h 2}\left(\bar{z}_{s 2}\right), \bar{z}_{s 2}\right)}{d \bar{z}_{s 2}}=\overbrace{\frac{\partial \pi_{h 2}}{\partial p_{h 2}} \frac{d p_{h 2}}{d \bar{z}_{s 2}}}^{\frac{\partial \pi_{h 2}}{\partial p_{h 1}} \frac{d p_{h 1}}{d \bar{z}_{s 2}}}+\overbrace{\frac{\partial \pi_{h 2}}{\partial \bar{z}_{s 2}}},
\end{aligned}
$$

\footnotetext{
${ }^{3}$ The strategy of restricting access to low-quality users has been studied in Hagiu [2009] in a context of two-sided platform competition. The platform may benefit from the exclusion of low-quality users on one side $i$ of the market when the users on the other side place more value on the average quality and less value on the total quantity on the side $i$.

${ }^{4}$ For notational convenience, the same subscript is used for the platform and a tablet.
} 
where (1) and (2) are the effects of a change in quality on tablet manufacturer profits, and (3) is the direct effect. For the envelope theorem, terms (1) are zero. Then, using the expressions for equilibrium prices and quantities found above, it is possible to show that the two differentials boil down to:

$$
\frac{d \pi_{h 1}}{d \bar{z}_{s 1}}=\frac{3}{2} \frac{p_{h 1}^{*}-c_{1}}{k} z_{h 1} \quad \text { and } \quad \frac{d \pi_{h 2}}{d \bar{z}_{s 2}}=\frac{17}{12} \frac{p_{h 2}^{*}-c_{2}}{k} z_{h 2}
$$

Hence, the producer of platform 1's tablets benefits more than platform 2's manufacturers if:

$$
p_{h 1}^{*}-c_{1}>\left(p_{h 2}^{*}-c_{2}\right) \frac{17}{18} \frac{z_{h 2}}{z_{h 1}}
$$

Under the very mild condition that Apple's hardware quality is larger than the average quality of Android tablets, $z_{h 1}>z_{h 2}$, a sufficient condition for platform 1 tablet producer gaining more benefits from an increase in apps quality than platform 2 tablet manufacturers is that the equilibrium mark-up in this platform is larger than the mark-up on platform 2. If this condition holds, then Apple tends to benefit more from an increase in app quality than the Android producers. The main reason lies in the presence of intra-platform competition among Android tablet producers, which, partially or entirely, washes away the potential benefits of an increase in the quality of Google Play apps that Android tablet producers can enjoy.

Wrapping-up, if we reinterpret the average user rating on platform $i$ as the average quality of apps on that platform, then the following testable predictions follow immediately:

Prediction 1 (Effects of app quality). Equilibrium quantities and manufacturer profits are affected by the quality of the apps distributed in the dedicated store. First, the amount of platform i tablets increases with the average users' app rating on the same platform and decreases with the average users' app rating on platform $j$ - in absolute values, owneffects are larger than cross effects. Second, the impact of application quality on tablet demand tends to be larger on platform 1 and, third, following an increase in app quality, platform 1 producer's profits increase more than platform 2's.

One of the most debated issues in network industries is that of interoperability or standardization of products/platforms. Interoperability is a characteristic of a product to work with other products or systems without any restrictions. Typically, network firms may benefit from interoperability as it allows users to enjoy a larger network benefit that firms can try to seize via appropriate commercial strategies. At the same time, though, fully interoperable products tend to be less differentiated to the detriment of the producers that are induced to compete more aggressively on prices. Interoperability/standardization is often achieved directly by the firms acting on the market. This is what happens with the creation of the so-called Standard Setting Organization, which has precisely the objective of coordinating companies towards reaching and maintaining a common standard. In many cases, however, companies fail to coordinate, and interoperability is eventually mandated by law or imposed by the regulator. 
In the tablet market, interoperability would mean that all the apps developed for one platform would also run on the tablets produced for the other platform and vice-versa. ${ }^{5}$ Hence, relevant for our scopes, interoperability affects the average degree of apps quality available to tablet users; in particular, tablet users of the platform characterised by apps of lower quality benefit from interoperability, as they enjoy the higher quality of the apps of the other store. At the same time, we assume that users of the high quality platform are unaffected by the policy as they continue to enjoy the higher quality of the apps published in their store. Therefore, we model interoperability by imposing that the average quality of the apps $i$ ) is the same in both stores and $i$ ) it is equal to the maximum average quality between the two stores.

In what follows, we study the impact of interoperability under the empirically relevant assumption that before the policy the average quality of the apps in platform 1 is larger than in platform $2: \bar{z}_{s 1}>\bar{z}_{s 2}$; hence, $\bar{z}_{s 1}$ is the common average apps quality when the policy is implemented.

Let us start with considering the impact on prices. Imposing condition $\bar{z}_{s 2}=\bar{z}_{s 1}$ in expression (2), we can obtain the equilibrium price of platform 1's tablets with interoperable apps, $p_{h 1 I}^{*}$. By subtracting $p_{h 1}^{*}$ it is easy to see that the policy impacts negatively on platform 1 price. $^{6}$ As expected, the equilibrium price of platform 1 's tablets decreases with platforms interoperability as the policy implies an improvement in the average quality of platform 2's apps, a fact that makes the tablets produced for this platform more competitive. Finally, note that as $p_{h 2}^{*}$ is entirely determined by intra-platform competition among Android-based tablet manufacturers, the policy does not impact the price of platform 2 tablets.

We can use expressions (3) and (4) to evaluate the impact on quantities. Replacing $\bar{z}_{s 2}$ with $\bar{z}_{s 1}$ we obtain the equilibrium quantities when the policy is introduced. From a comparison of the output levels before and after the introduction of interoperability, it is easy to check that, as expected, the policy positively affects the demand of platform 2 tablets while it reduces the demand for platform 1 tablets: ${ }^{7}$

Prediction 2 (Interoperability). Interoperability: i) decreases the equilibrium price and quantity of platform 1's

\footnotetext{
${ }^{5}$ Equivalent to interoperability would be a situation where all developers multihome, which is developing apps in both iOS and Android format. Developers benefit from multihoming as it allows them to reach a larger number of users. Usually, they develop their app for one platform and, eventually, they translate it ("port" in the app jargon) into the alternative operating system. Unfortunately, porting an app can be very costly for developers, and this drives the tablet platforms away from achieving an interoperablelike equilibrium. Recently, new tools have been developed that considerably reduce the cost of developing multihoming apps. See valianttechnosoft.com/blog/why-you-should-consider-flutter-mobile-app-development-2020.

${ }^{6}$ Formally, with interoperability, the price of platform 1 tablets is
}

$$
\frac{3 c_{1}+c_{2}}{6}+\frac{t+n\left(3 z_{h 1}-z_{h 2}\right) \bar{z}_{s 1}+k n\left(l_{2}-l_{1}\right)}{6 n} .
$$

Subtracting from this expression, the equilibrium price of platform 1 tablets when platforms are not interoperable, it is easy to see that this difference is $z_{h 2}\left(\bar{z}_{s 2}-\bar{z}_{s 1}\right) / 6<0$, which is clearly negative.

${ }^{7}$ Formally, indicating with $q_{h j I}^{*}$ the amount of platform $i$ 's tablets with interoperability, it turns out that for $z_{h 1}>z_{h 2}$ : $q_{h 1 I}^{*}-q_{h 1}^{*}=$ $z_{h 2}\left(\bar{z}_{s 2}-\bar{z}_{s 1}\right) /(4 k)<0$, and $q_{h 2 I}^{*}-q_{h 2}^{*}=17 z_{h 2}\left(\bar{z}_{s 1}-\bar{z}_{s 2}\right) /(12 k)>0$. Using these expressions, one can notice that the overall impact of the policy is $\left(q_{h 1 I}^{*}-q_{h 1}^{*}\right)+\left(q_{h 2 I}^{*}-q_{h 2}^{*}\right)=7\left(\bar{z}_{s 1}-\bar{z}_{s 2}\right) /(6 k)$, which is clearly positive. 
tablets, ii) it does not affect the equilibrium price of platform 2's tablets and it increases the quantity of platform 2 tablets, and iii) it stimulates the overall demand for tablets.

Our prediction allows us to make two interesting observations on the social desirability of the introduction of the policy. Prediction 2iii) reveals that the overall demand for tablets increases when platforms are interoperable. In other words when, with incompatible platforms, the average quality of the apps on platform 1 is higher then on platform 2, interoperability has the remarkable effect of stimulating the adoption of tablet technologies.

The second observation follows directly from Predictions $2 i$ ); when the two platforms are interoperable, consumer welfare is necessarily higher; as a matter of fact, with interoperability, $p_{h 1}^{*}$ is reduced, while $p_{h 2}^{*}$ remains unchanged, thus overall benefiting consumers.

\section{Econometric model}

We present the econometric model in four parts.

\subsection{Empirical demand functions}

There are $T$ country-period markets, each having $I_{t}$ consumers. The consumer $i$ from market $t$ can choose between buying one of the $J_{t}$ new tablets, $j=1,2, \cdots, J_{t}$ or a composite outside good $j=0$. The indirect utility associated with buying tablet $j$ in market $t$ is expressed as

$$
u_{i j t}=x_{j t} \beta_{i}+\xi_{j t}+\zeta_{i g t}+(1-\rho) \epsilon_{i j t},
$$

where $x_{j t}$ is a $1 \times K$ vector of observed tablet characteristics, among which the price and the quality of mobile applications. Some of the tablet characteristics are market-invariant; others, like the price, tend to vary both over market and product or over market and group $(g)$ of products in case of mobile application quality. The group for this typology of products is defined according to the operating system. Not all of the product characteristics are observed by the researcher, and those that are not observed are captured by the variable $\xi_{j t}$. The $K \times 1$ parameters $\beta_{i}$ s are random coefficients. The term $\zeta_{i g t}$ is common to all the products that use the same operating system in the market and is a random variable with a probability distribution function that depends on the within-group correlation parameter $\rho$, with $0 \leq \rho<1$. The idiosyncratic error term $\epsilon_{i j t}$ is assumed to be identically and independently distributed extreme value, and so is the composite term $\zeta_{i g t}+(1-\rho) \epsilon_{i j t}$ [see Cardell, 1997]). As in Nevo [2001] the random coefficients are given by the sum of means, $\beta \mathrm{s}$, and dispersions around these means-these latter decomposed in the result of $M \times 1$ observable demographics $d_{i}$ and $K \times 1$ unobservable variables of individual heterogeneity $v_{i}$, drawn from a 
multivariate standard normal:

$$
\beta_{i}=\beta+\Pi d_{i}+\Sigma v_{i}
$$

The matrix of parameters $\Pi$ has dimension $K \times M$, and $\Sigma$ is $K \times 1$ diagonal matrix of standard deviations $\sigma$ s. Equations (7) and (8) describe the Random Coefficients Nested Logit (RCNL) model introduced by Grigolon and Verboven [2014]. Restrictions to the random coefficients lead to the nested logit (NL) specification. In our empirical section, we will estimate both NL and RCNL models.

The consumer $i$ in market $t$ chooses the product $j$ that gives the highest utility. In the case of the RCNL model, the conditional probability of that choice is,

$$
\phi_{i j t}\left(x_{t}, \xi_{t}, d_{i}, v_{i}, \theta\right)=\frac{\exp \left(\left(x_{j t} \beta_{i}+\xi_{j t}\right) /(1-\rho)\right)}{\exp \left(I_{i g} /(1-\rho)\right)} \frac{\exp \left(I_{i g}\right)}{\exp \left(I_{i}\right)}
$$

where $\theta=\{\beta, \vec{\Pi}, \sigma, \rho\}$, with $\vec{\Pi}$ denoting the vectorization of $\Pi$. McFadden's (1978) inclusive values $I_{i g t}$ and $I_{i t}$ are the result of the log sums:

$$
\begin{aligned}
I_{i g t} & =(1-\rho) \ln \sum_{l=1}^{J_{g t}} \exp \left(\left(x_{l t} \beta_{i}+\xi_{l t}\right) /(1-\rho)\right), \\
I_{i t} & =\ln \left(1+\sum_{g=1}^{G_{t}} \exp \left(I_{i g t}\right)\right) .
\end{aligned}
$$

The upper limit $J_{g t}$ in the summation of $I_{i g t}$ is the total number of products in the group $g$ in market $t$, and the 1 entering $I_{i t}$ is the effect of the exponential of the outside group $g=0$ normalised to zero, since this contains only the outside good, $u_{i 0 t}=\zeta_{i 0 t}+(1-\rho) \epsilon_{i 0 t}$.

The market share of the product $j$ in market $t, s_{j t}$, can be obtained by integrating equation (9) with respect to the distribution of $d_{i}$ and $v_{i}$, whose solution can be approximated by Monte Carlo simulations [see Nevo, 2001, Berry et al., 1995]). To estimate the parameters $\theta$ Grigolon and Verboven [2014] propose an extension of the contraction mapping technique put forward by Berry et al. [1995]. To explain their extension, we label with $\delta_{j t}$ the mean utility of equation (7), i.e. $\delta_{j t}=x_{j t} \beta+\xi_{j t}$. The contraction mapping in case of RCNL model for the $J_{t} \times 1$ vector of mean utilities is

$$
\delta_{t}^{r+1} \equiv \delta_{t}^{r}+(1-\rho)\left[\ln \left(s_{t}\right)-\ln \left(s_{t}\left(\delta_{t}^{r}\right)\right)\right]
$$

Convergence is reached when for each market $t, \delta_{t}^{r+1} \approx \delta_{t}^{r}$. Upon convergence, it is possible to recover the unobserved 
heterogeneity that goes in the mean utility term, $\xi_{j t}$. The interaction of this variable with a set of instruments gives the moment conditions that enter the GMM function.

\subsection{Empirical pricing equations}

Multiproduct tablet producers observe the demand for tablets and choose the price that maximizes their profit, given the prices and characteristics of the other products in the market. The marginal cost of producing tablet $j$ in market $t, c_{j t}$ is assumed to be constant in output. The tablet manufacturer $m$ in market $t$ produces a set $\mathcal{J}_{m t}$ of $J_{t}$ new tablets. Given the demand (share) function that derives from integrating equation (9), the profit of tablet manufacturer $m$ is:

$$
p_{j t}(\cdot)=\underset{p_{j t} \geq 0}{\arg \max } \pi_{m t}=\sum_{r \in \mathcal{J}_{m t}}\left(p_{r t}-c_{r t}\right) s_{r t} I_{t} \quad \text { with } \quad j, r \in \mathcal{J}_{m t} .
$$

The first-order conditions $\forall j \in \mathcal{J}_{m t}$ and $\forall m$ are:

$$
s_{j t}+\sum_{r \in \mathcal{J}_{m t}}\left(p_{r t}-c_{r t}\right) \frac{\partial s_{r t}}{\partial p_{j t}}=0 .
$$

Upon defining $\Delta_{t}$ a $J_{m t} \times J_{m t}$ matrix whose $(j, r)$ element is $\Delta_{j r}=-\frac{\partial s_{r t}}{\partial p_{j t}}$ if $r \neq j \in \mathcal{J}_{m t}$ and zero otherwise, the first order conditions given above can be written in matrix notation as the system of pricing equations:

$$
p_{t}=\underbrace{\Delta_{t}^{-1} s_{t}}_{m u p_{t}+c_{t}} .
$$

We assume the marginal cost to be a linear function of observable product characteristics $w_{t}$ and the random component $\omega_{t}$. Yielding:

$$
p_{t}=\operatorname{mup}_{t}+w_{t} \gamma+\omega_{t}
$$

\subsection{Joint nonlinear GMM estimator}

In our empirical exercise, we assume that the variables that go in the exogenous demand vector $\tilde{x}$ are the variables that enter the demand $x$ with the exclusion of app quality and the price $(p)$. The vector $\tilde{x}$ includes a constant, storage capacity, screen resolution, screen size and type of connection, and dummies for time, firm, and country. ${ }^{8}$ The same variables enter the marginal cost function, i.e. $w=\tilde{x}$. Only the price variable has a random coefficient, ${ }^{9}$, and we use

\footnotetext{
${ }^{8}$ Firms that sell less than three products are part of a residual category.

${ }^{9}$ We experimented by adding a random coefficient to app quality, but the estimated standard deviation was always close to zero. Eventually, we opted for removing that random coefficient to speed-up the estimation procedure. Adding other random coefficients would have made the estimation
} 
only income as demographics. In terms of the notation above, we have that $M=1$. Assuming that price is the last variable entering the vector of all observable characteristics $x$, then $\Pi$ is a vector of zeros apart from the last element, and this is also the case for the vector $\sigma$. Thus, the set of all parameters $\theta=\left\{\beta, \gamma, \pi_{p}, \sigma_{p}, \rho\right\}$. There are only two groups ( $G=2$ operating systems) in addition to the outside good group, and these are iOS and Android.

Both the unobserved heterogeneity from the demand side, $\xi_{j t}$, and the unobserved heterogeneity from the pricing equation, $\omega_{j t}$, are random variables. Denote the vector of exogenous variables in market $t$ with $z_{t}=\left[\tilde{x}_{1 t}, w_{1 t}, \cdots, \tilde{x}_{J_{t} t}, w_{J_{t} t}\right]$, and that for all markets as $z=\left[z_{1}, \cdots, z_{T}\right]$. We work with the assumption of conditional independence of the type, $E\left(\xi_{j t} \mid z_{t}\right)=E\left(\omega_{j t} \mid z_{t}\right)=0$. In the estimation procedure we account for correlation between the demand and pricing equations making use of Choleski factorization $T_{t}$ of the inverse of the covariance matrix $\Omega\left(z_{t}\right)=E\left(\left(\xi_{j t}, w_{j t}\right)^{\prime}\left(\xi_{j t}, w_{j t}\right) \mid z_{t}\right)$. Defining with $H_{j t}\left(z_{t}\right)$ the $L \times 2$ matrix of instruments, it is possible to write the set of moment conditions as

$$
G_{t}=E_{j}\left(H_{j t}\left(z_{t}\right) T\left(z_{t}\right)\left[\begin{array}{c}
\xi_{j t} \\
\omega_{j t}
\end{array}\right]\right) .
$$

Upon generalising the moment conditions $G_{t}$ to all markets $G=\left[G_{1}, \cdots, G_{T}\right]$, the function to be minimised is

$$
\min _{\theta} E_{t}\left(G^{\prime} G\right)
$$

The first-order conditions of equation (17) are linear in the $\beta$ parameters (excluding the price coefficient, $\beta_{p}$, as this one enters non-linearly in the pricing equations) and the $\gamma$ parameters, and are nonlinear for all other parameters entering $\theta$. This will simplify the estimation procedure by allowing us to partition out the linear parameters and concentrate the nonlinear search on the other parameters: $\beta_{p}, \pi_{p}, \sigma_{p}, \rho$.

An issue in demand estimation is the price endogeneity caused by the correlation between unobserved (to the researcher) product characteristics and the price due to omitted tablet quality. This correlation may lead to an upward bias of the price parameter estimated using OLS due to a positive correlation between price and quality. As a consequence, the markup derived from the pricing equations will be overestimated and cause a large number of negative marginal costs. The empirical IO literature has advanced instruments able to cope with this endogeneity [see Hausman and Taylor, 1981, Berry, 1994, Berry et al., 1995, Berry and Haile, 2014]. Besides the price endogeneity, the effect of application quality also raises concerns of endogeneity since the unobserved tablet quality can drive tablet sales and, consequently, tablet installed base, which impacts the decision of developers to produce higher-quality applications. Following the previous literature [see Nair et al., 2004, Corts and Lederman, 2009], we employ the average tablet characteristics of products within the same segment as instruments for application quality. 


\subsection{Instruments}

We use instruments to deal with the aforementioned endogeneity. In the nested logit version of the demand estimation, the price endogeneity has a direct effect but also an indirect effect as prices enter the within segment market shares, making this to be endogenous too. Following previous related literature, we employ two sets of instruments: BLP-type and Hausman and Taylor [1981]-type. The BLP-type instruments are computed as the sum of each observed product characteristic (excluding the price and app quality) over the set of other tablets produced by the same manufacturer. To deal with the endogeneity of within-product market shares, we refine the logic to products sold by other manufacturers in the same segment. These instruments assume that they are the result of long-term decisions, and in the short term, they are assumed to be uncorrelated time-varying unobserved product heterogeneity. Based on this assumption, the above instruments are exogenous and meet the independent moment conditions. The Hausman and Taylor's 1981-type instruments exploit the assumption that multi-product firms have a common cost structure and, once we control for the firm fixed effect, the average price of other products by the same firm can be used as an instrument.

We also employ the regression tree approach [Leo Breiman and Olshen, 1984] to capture any non-linear effects of tablet characteristics on prices and within market shares. This process enables us to generate a set of instruments for both prices and within market shares as follows. The list of instruments in addition to $\tilde{x}$ are $h_{1}$ (sum of the screen size of other products by the same firm), $h_{2}$ (average price of other products in other markets by the same firm), $h_{3}$ (sum of screen resolution $(\log )$ of other products by the same firm), $h_{4}$ (average screen resolution of products within the same segment), $h_{5}$, (average screen size of products within the same segment), $h_{6}$, (average storage of products within the same segment) and three instruments constructed using a regression tree approach: $h_{8}$ (a dummy taking value one if Storage $>12$ and zero otherwise), $h_{9}$, (a dummy taking value one if Storage $>48$ and Screen size $>7.9$ and zero otherwise), and $h_{10}$, (a dummy taking value one if Storage $\geq 24$ and zero otherwise).

The instruments listed above form the $H_{j t}$ matrix that enters the moment conditions of equation (16).

\section{Data}

In our empirical work, we combine three datasets. We use a dataset on the new tablet market maintained by IDC CEMA, which contains product-level information on tablet characteristics such as model name, model ID, producer, operating system (OS), CPU type, connectivity, screen size, screen resolution, storage, prices and unit sales for five European countries. The countries are France, Germany, Spain, Italy, and the UK. The original dataset is a panel of 15 quarters, starting from 2010Q3 and ending with 2014Q1. A total of 775 different products are observed during this time frame and countries. These products yield 12,337 observations due to their various specs. These products are produced by 45 different vendors and are compatible with one of six operating systems: Android, iOS, Blackberry OS, Windows, Windows RT, webOS. 
In Figure 1, we show the time trend of unit sales and the average price for each of the five European country markets. As can be seen from a comparison of subfigures (a) and (b), the unit sales of iPad exceed those of Android until 2012Q2. Thereafter, the sales of Android-based tablets rise dramatically, to exceed those of iOS. This is consistent with the different strategies adopted by the two platforms. Apple entered first in the market with its first generation of iPad launched in April 2010; followed later that year by the Android-based Galaxy Tab. However, due to a lack of high-quality tablet applications, the rise in sales was slow for Android-based tablets. App developers were hesitant to develop applications for a small market (typical network effects problem). The strategy of distributing Android as an open platform licensed for free to many tablet producers, against iOS vertically integrated by Apple, paid back over time in terms of market share. The number of Android tablet models evolved more rapidly than that of iOS models, resulting in higher unit sales. Seasonality is also noticeable in the figures, with clear Christmas period peaks.

The time trend for the average price is opposite between the two OSs, dropping for iOS and rising for Androidbased models. The initial drop in average price by Apple was due to its strategy to launch first a high-quality iPad, followed by smaller size and cheaper iPad models (iPad mini). Instead, Android tablets initially targeted the low-quality segment of the market (also due to the limited number of high-quality mobile applications first and then expanded the versions towards middle and high-quality segments. From mid-2012, the average price of both iPad and Android tablets became stable over time, and the iPad maintaining a significantly higher average price. Except for the last quarter of each year, the statistics in all other quarters are consistent with the nature of the demand: when the price falls/rises, sales surge/drop.

In terms of operating system (OS), our data shows that iOS and Android-based tablets ended up dominating the market: unit sales of iOS and Android tablets in 2014Q1 are 1,035,642 and 709,961 respectively, whereas there are only 15,040 unit sales of other OS tablets.

The second dataset that we use is made of mobile application data. This dataset, assembled by Priori Consulting Analytics, is made of six-monthly panels of top 1,000 ranked (based on downloads) apps in Google Play and Apple Store in each of the five European countries mentioned earlier. The period covered by the data is 2013M9-2014M2. Our interest in this dataset is in this work limited to have a measure of app quality. After tablet users download and use a mobile application, they are asked to write a review and rate that app on a scale of one to five. The average rating of users of an app is an indicator of how good and reliable the app is; hence, for each market (country-period), we compute the weighted average app rating of the apps where each app is weighted by its downloads and use this as a proxy of the average quality of the apps distributed in the store. We weight apps by their downloads to account for the fact that popular apps contribute more to the determination of the average quality than less popular ones; nonetheless, in the appendix, we show how results change if we use other metrics, such as the median of customer ratings, the weighted average rating of top apps, etc. 


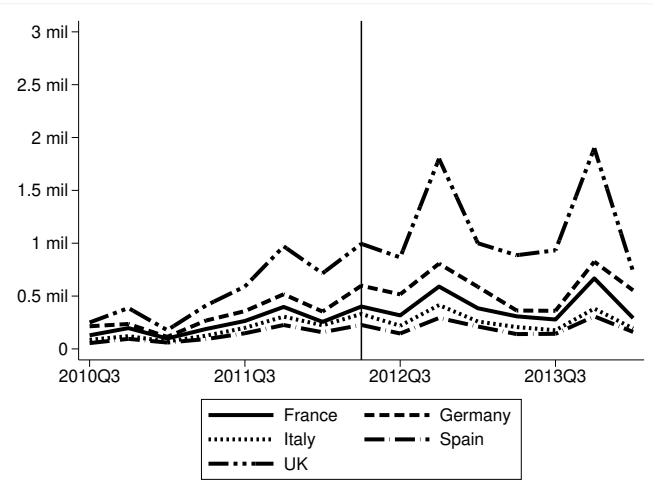

(a) iPad unit sales

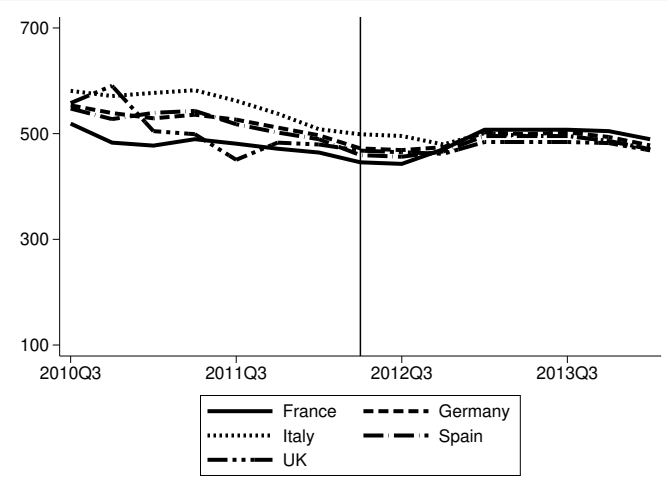

(c) Average price iPad

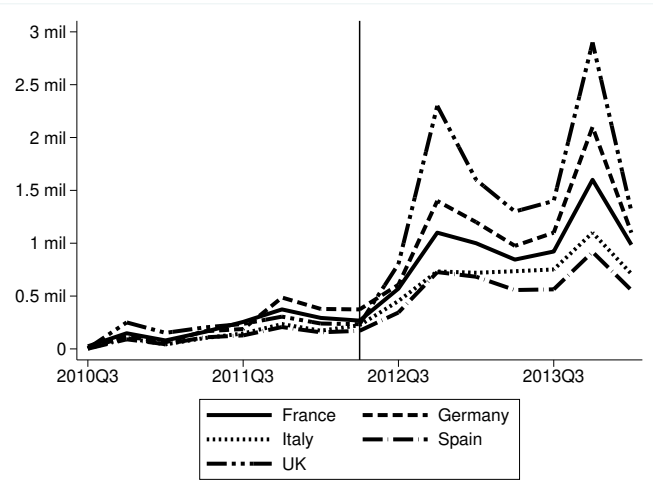

(b) Android tablet unit sales

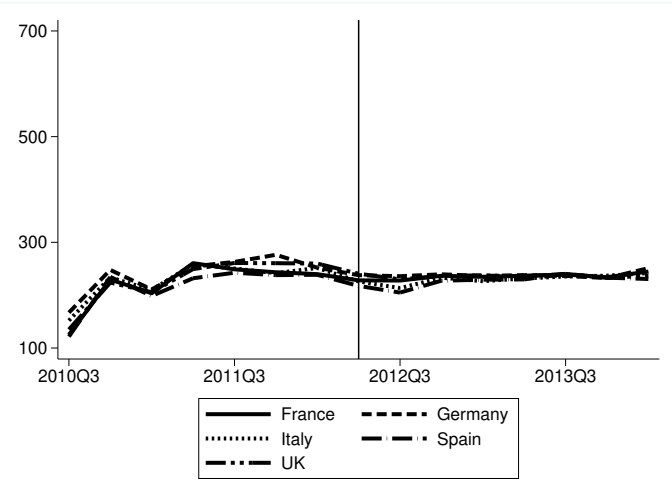

(d) Average Android tablet prices

Figure 1: Tablet unit sales and average prices in five countries between 2010Q3 and 2014Q1

Figure 2 displays the weighted average app rating by period and country (by market). In most countries, the weighted average rating in the Google Play store is slightly higher than that in Apple Store in the early period and becomes lower than in Apple Store in the last period in all countries. The rating of an app is country invariant. Thus, variation in rating across countries is only possible if countries have a different portfolio of top apps. This is the case in our data for two reasons. First, because it is not necessarily that an app is top in all countries in the same period (or in any period) and second, equally important because there are apps that are local and therefore distributed only in that country. ${ }^{10}$ As can be seen in Figure 2, there is a variation of app ratings both over time and across countries.

The third dataset is given by consumer demographics obtained from Eurostat, European Union Statistics on Income and Living Condition (EU-SILC) survey 2013. This survey data consists of cross-section and longitudinal multidimensional microdata on labour, education, health, income, poverty, social exclusion, and living conditions in all EU countries. While the information on labour, education, and health are collected at the individual level, social exclusion and living conditions information is obtained at the household level. Our variable of interest, income, is decomposed

\footnotetext{
${ }^{10}$ In our dataset an app is defined as local if it generates more than $40 \%$ of its revenues within a single country.
} 


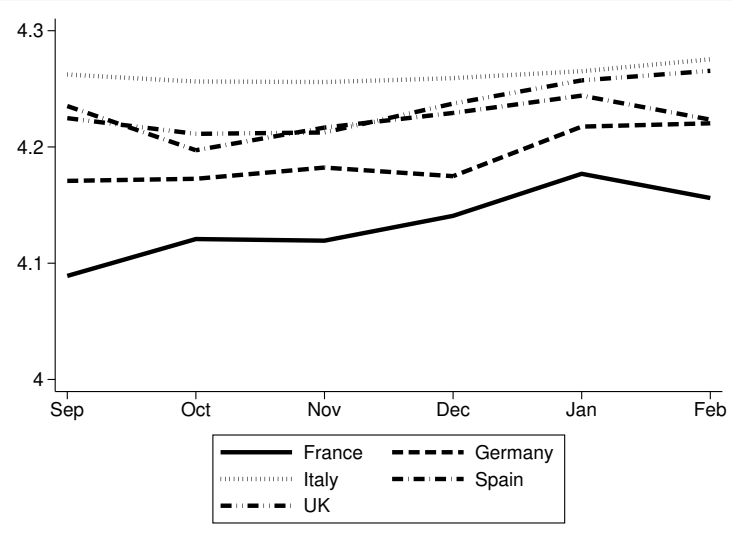

(a) Apple Store

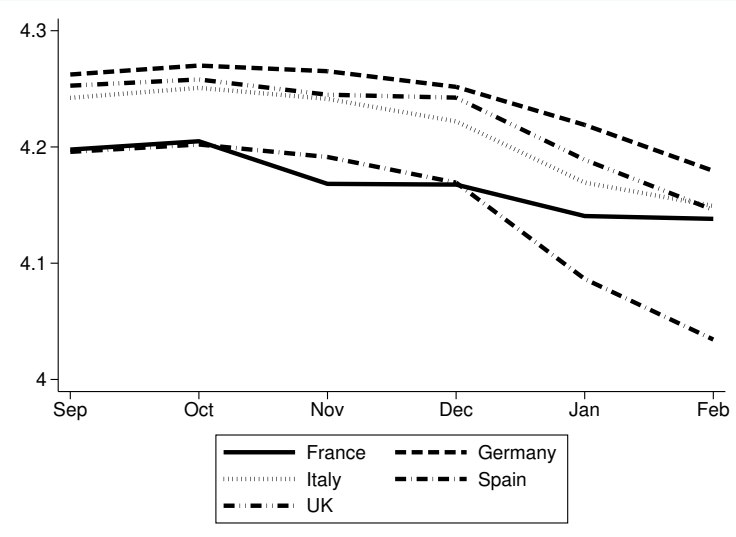

(b) Google Play

Figure 2: The average rating of the top 1000 ranked apps in the App Store and Google Play in 5 countries Sep 2013 Feb 2014

into detailed components such as gross cash or near-cash employee income, gross non-cash employee income, etc., and collected at personal levels. We sum all the income components to obtain the individual income levels and use a random sample of this variable in our analysis.

\subsection{Combining the datasets}

Since one of the main objectives of the paper is to estimate the effect of app quality on tablet demand, we need to impose the datasets to overlap on the time units and countries. We do not have a problem with spatial overlapping since all the aforementioned datasets cover the same five European countries. Unfortunately, this is not the case for the time dimension. For the demographics dataset, this is less of a problem since, in the relatively short period of time of our analysis (max four years), we can assume that there is a limited variation in the distribution of demographics. The main limitation is on how to combine the mobile application data and the tablet data. We are forced to map six months onto three quarters and therefore disregard the other quarterly data on tablets. In an attempt to have enough overlapping periods for calculating the effect of quality we select three months that overlap with three quarters. These are 2013M9, 2013M11, and 2014M2 and match these to the quarters of tablet data 2013Q3, 2013Q4, and 2014Q1. The number of observations on tablets narrows down from 12,337 to 4,849. Furthermore, since only data for applications distributed in the App Store and Google Play are observed, the tablet observations need a further cut to be associated with models compatible with these two stores. Finally, we drop 54 tablet models that have too tiny market shares, in order to avoid outliers in our estimation. This leaves us with 3,753 tablet observations.

The market size is assumed to be half of a country's population. Given this assumption, the market share of each tablet model in a period can be calculated by taking the ratio between the unit sales and the market size. The summary 


\section{Table 1}

Summary statistics of relevant variables

\begin{tabular}{lccccc}
\hline \hline & $\mathrm{N}$ & Mean & Std.dev & Min & Max \\
\hline Key variables & & & & & \\
market share (s) & 3753 & $4.27 \mathrm{E}-04$ & 0.001 & $1.48 \mathrm{E}-07$ & 0.023 \\
price (p) & 3753 & 261.830 & 167.860 & 37.740 & 1050.000 \\
screen size & 3753 & 8.648 & 1.366 & 7.000 & 13.300 \\
storage & 3753 & 20.846 & 19.401 & 0.512 & 128.000 \\
log screen resolution & 3753 & 13.835 & 0.658 & 12.858 & 15.226 \\
connectivity & 3753 & 1.344 & 0.475 & 1.000 & 2.000 \\
app rating & 3753 & 4.196 & 0.059 & 4.034 & 4.275 \\
\hline
\end{tabular}

Notes: Connectivity is 1 if the connectivity is WIFI and 2 if WIFI/3G or $\mathrm{WIFI} / 4 \mathrm{G}$. We take the log of the product of width and height for the value of screen resolution. For example, the resolution $1920 \times 1080$ will be $\log (1920 \times 1080)$.

statistics of the variables that will be used in the estimation are documented in Table 1.

Finally, from the survey on consumer data, we randomly draw 100 individuals for each of the five countries. To avoid issues that may arise by having too large values of income (outliers) in the estimation, we restrict the income variable to its $5^{\text {th }}$ and $95^{\text {th }}$ percentile (5,000 and 100,000 EUR, respectively). We then rescale income by dividing it by 100,000 . In the regressions, we interact with income price and application rating. As our timeline lasts only for three quarters, we assume that the income of individuals is permanent.

\section{Results}

In this section, we first present the results of the joint demand and supply equation estimations for tablets and then discuss the counterfactual analysis aimed at studying the role of app quality. The estimations of the demand for tablets and of the pricing equation are documented in Table 2.

The first pairs of columns show the results of a simple OLS estimation of nested logit tablet demand and supply without controlling for the endogeneity of price, within the market share, and application quality. Most of the estimated coefficients on the demand side, especially the estimated coefficient for application quality, are not statistically significant due to the problem of endogeneity. Ignoring this problem leads to biased estimates, which results in a large number (about $28 \%$ ) of negative marginal costs. On the other hand, the price coefficient and within nest correlation parameter have the expected sign and range and are statistically significant.

The next two pairs of columns present the results of nested logit joint demand and supply IV GMM estimate without and with controlling for the endogeneity of application quality. The IV GMM estimator reduces the bias and greatly improves the efficiency of the estimates, as the number of negative marginal costs have gone down significantly compared to the least-squares version. The estimated coefficients of the two specifications differ, especially that of 
Table 2

Joint estimation results

\begin{tabular}{|c|c|c|c|c|c|c|c|c|c|c|}
\hline & \multicolumn{2}{|c|}{ OLS NL } & \multicolumn{2}{|l|}{ NL } & \multicolumn{2}{|l|}{$\mathrm{NL}^{e}$} & \multicolumn{2}{|c|}{ RCNL } & \multicolumn{2}{|c|}{$\mathrm{RCNL}^{e}$} \\
\hline & $\begin{array}{c}\text { Parameter } \\
\text { (1) }\end{array}$ & $\begin{array}{l}\text { SE } \\
(1)\end{array}$ & $\begin{array}{c}\text { Parameter } \\
\text { (2) }\end{array}$ & $\begin{array}{l}\mathrm{SE} \\
(2)\end{array}$ & $\begin{array}{c}\text { Parameter } \\
\text { (3) }\end{array}$ & $\begin{array}{l}\text { SE } \\
(3)\end{array}$ & $\begin{array}{c}\text { Parameter } \\
\text { (4) }\end{array}$ & $\begin{array}{l}\text { SE } \\
(4)\end{array}$ & $\begin{array}{c}\text { Parameter } \\
\text { (5) }\end{array}$ & $\begin{array}{l}\text { SE } \\
(5)\end{array}$ \\
\hline \multicolumn{11}{|c|}{ Demand side } \\
\hline Constant & $-16.831 * *$ & 0.499 & $-3.585 * *$ & 0.028 & $-9.880 * *$ & 0.032 & $-10.543 * *$ & 3.349 & $-13.899 * *$ & 0.032 \\
\hline Storage & -0.002 & 0.003 & 0.001 & 0.001 & 0.001 & 0.001 & 0.006 & 0.005 & $0.006 * *$ & 0.001 \\
\hline Screen resolution & $0.827 * *$ & 0.047 & $0.186 * *$ & 0.047 & $0.493 *$ & 0.208 & $0.370 * *$ & 0.096 & $0.546 * *$ & 0.047 \\
\hline Screen size & 0.015 & 0.022 & 0.013 & 0.015 & $0.084 * *$ & 0.014 & 0.087 & 0.047 & $0.102 * *$ & 0.016 \\
\hline Connection & 0.098 & 0.069 & 0.054 & 0.040 & 0.057 & 0.040 & 0.258 & 0.151 & $0.288 * *$ & 0.043 \\
\hline Application quality & -0.196 & 0.321 & $-0.536 * *$ & 0.130 & $1.077^{* *}$ & 0.135 & 0.376 & 0.205 & $0.700 *$ & 0.306 \\
\hline Price $\left(\beta_{\mathrm{p}}\right)$ & $-0.008 * *$ & 0.000 & $-0.002 * *$ & 0.000 & $-0.018 * *$ & 0.000 & $-0.006 * *$ & 0.002 & $-0.009 * *$ & 0.000 \\
\hline Price $\left(\sigma_{\mathrm{p}}\right)$ & & & & & & & 0.006 & 0.044 & $0.006 * *$ & 0.001 \\
\hline Price $\left(\pi_{\mathrm{p}}\right)$ & & & & & & & $0.011 * *$ & 0.004 & $0.013^{* *}$ & 0.001 \\
\hline Correlation $\rho$ & $0.264 *$ & 0.104 & $0.859 * *$ & 0.018 & $0.885^{* *}$ & 0.001 & $0.740 * *$ & 0.108 & $0.754 * *$ & 0.016 \\
\hline \multicolumn{11}{|c|}{ Pricing equation } \\
\hline Constant & $-12.585 * *$ & 0.037 & $-7.228 * *$ & 0.157 & $0.023 * *$ & 0.001 & 0.314 & 0.482 & $0.581 * *$ & 0.058 \\
\hline Storage & $0.016 * *$ & 0.001 & $0.029 * *$ & 0.001 & $0.473 * *$ & 0.002 & 0.004 & 0.011 & 0.004 & 0.002 \\
\hline Screen resolution & $0.762 * *$ & 0.037 & $0.516 * *$ & 0.037 & $0.237 * *$ & 0.015 & $0.233 * *$ & 0.072 & $0.237 * *$ & 0.018 \\
\hline Screen size & $0.384 * *$ & 0.016 & $0.263 * *$ & 0.015 & $0.628 * *$ & 0.034 & 0.114 & 0.117 & $0.113^{* *}$ & 0.024 \\
\hline Connection & $0.882 * *$ & 0.035 & $0.681 * *$ & 0.034 & 0.061 & 0.117 & $0.269 *$ & 0.137 & $0.265 * *$ & 0.052 \\
\hline \multicolumn{11}{|c|}{ Model Statistics } \\
\hline $\mathrm{N}$ & \multicolumn{2}{|l|}{3753} & \multicolumn{2}{|c|}{3753} & \multicolumn{2}{|l|}{3753} & \multicolumn{2}{|c|}{3753} & \multicolumn{2}{|c|}{3753} \\
\hline Pseudo $\mathrm{R}_{D}^{2}$ & \multicolumn{2}{|l|}{0.684} & \multicolumn{2}{|c|}{0.987} & \multicolumn{2}{|l|}{0.989} & \multicolumn{2}{|c|}{0.697} & \multicolumn{2}{|c|}{0.715} \\
\hline Pseudo $\mathrm{R}_{S}^{2}$ & \multicolumn{2}{|l|}{769} & \multicolumn{2}{|c|}{0.678} & \multicolumn{2}{|l|}{0.702} & \multicolumn{2}{|c|}{0.681} & \multicolumn{2}{|c|}{0.662} \\
\hline J-stat $\quad S$ & \multicolumn{2}{|l|}{$5 E-15$} & \multicolumn{2}{|c|}{2.121} & \multicolumn{2}{|l|}{2.664} & \multicolumn{2}{|c|}{13.446} & \multicolumn{2}{|c|}{11.826} \\
\hline $\mathrm{N} \mathrm{mc}<0$ & \multicolumn{2}{|l|}{1049} & \multicolumn{2}{|c|}{431} & \multicolumn{2}{|l|}{368} & 8 & & & \\
\hline Average price-cost margin & 0.513 & & $0.46 C$ & & 0.429 & & 0.272 & & 0.2 & \\
\hline
\end{tabular}

application quality. Without controlling for the endogeneity, the coefficient of app quality is underestimated and turns out to be negative. After addressing the endogeneity issue, the coefficient of application quality becomes positive and significant. This finding confirms that the demand for tablets is affected by the quality of available apps. The estimated within-segment coefficient, $\rho$, is above 0.85 in both specifications, which is considerably higher than in the benchmark OLS specification.

Controlling for the endogeneity of within market shares has corrected the downward bias of the OLS estimates. The estimated $\rho$ parameter is statistically significant both from zero and one-implying a strong within-group (operating system) correlation of individual preferences. The joint estimation of demand and supply and the IV approach has tackled the issue of endogenous price. The coefficient is negative and significant. However, the price coefficient in all nested logit specifications is relatively small in absolute value, and the price elasticity of demand is not sufficiently picked by the within market share correlation coefficient, resulting in a great number of negative marginal costs also after correcting for the endogeneity (431 and 368, respectively).

The results of the random coefficients nested logit (RCNL) model with and without controlling for the endogeneity of application quality are presented in the pairs of columns (4) and (5). The first rows of results are the mean 
marginal effect on the utilities $(\beta \mathrm{s})$. Both estimations show a similar estimated coefficient on the tablet characteristics like storage, connection, screen resolution, and screen size, with the former generating smaller standard errors. After accounting for the endogeneity of application quality, the estimated app quality parameter becomes statistically significant. The results suggest that treating application quality as exogenous would lead to biased estimates. Solving this issue also leads to more efficient estimates. The number of negative marginal costs drops from above 350 in the NL specification to only 8 in RCNL. For this reason, we choose RCNL as our preferred model. In comparison with the Nested Logit model, the nesting parameter in RCNL remains highly statistically significant from zero and one, but the magnitude is smaller. Along with this parameter, our main focus is on the price parameters. The mean coefficient on the price $\left(\beta_{\mathrm{p}}\right)$ is negative and statistically significant. The dispersion around the mean price effect induced by the unobserved and observed individual characteristics (recall that we only control for one individual characteristic, which is income) are all significant. As one would expect, high-income individuals are less elastic to price changes. Figure (3) pictures the distribution of price sensitivity for all markets. There is sufficient heterogeneity of price sensitivity. Due to the skewed distribution of the price effect of RCNL, it is not a surprise that the magnitude of the estimated mean price coefficient of RCNL differs from that of NL.

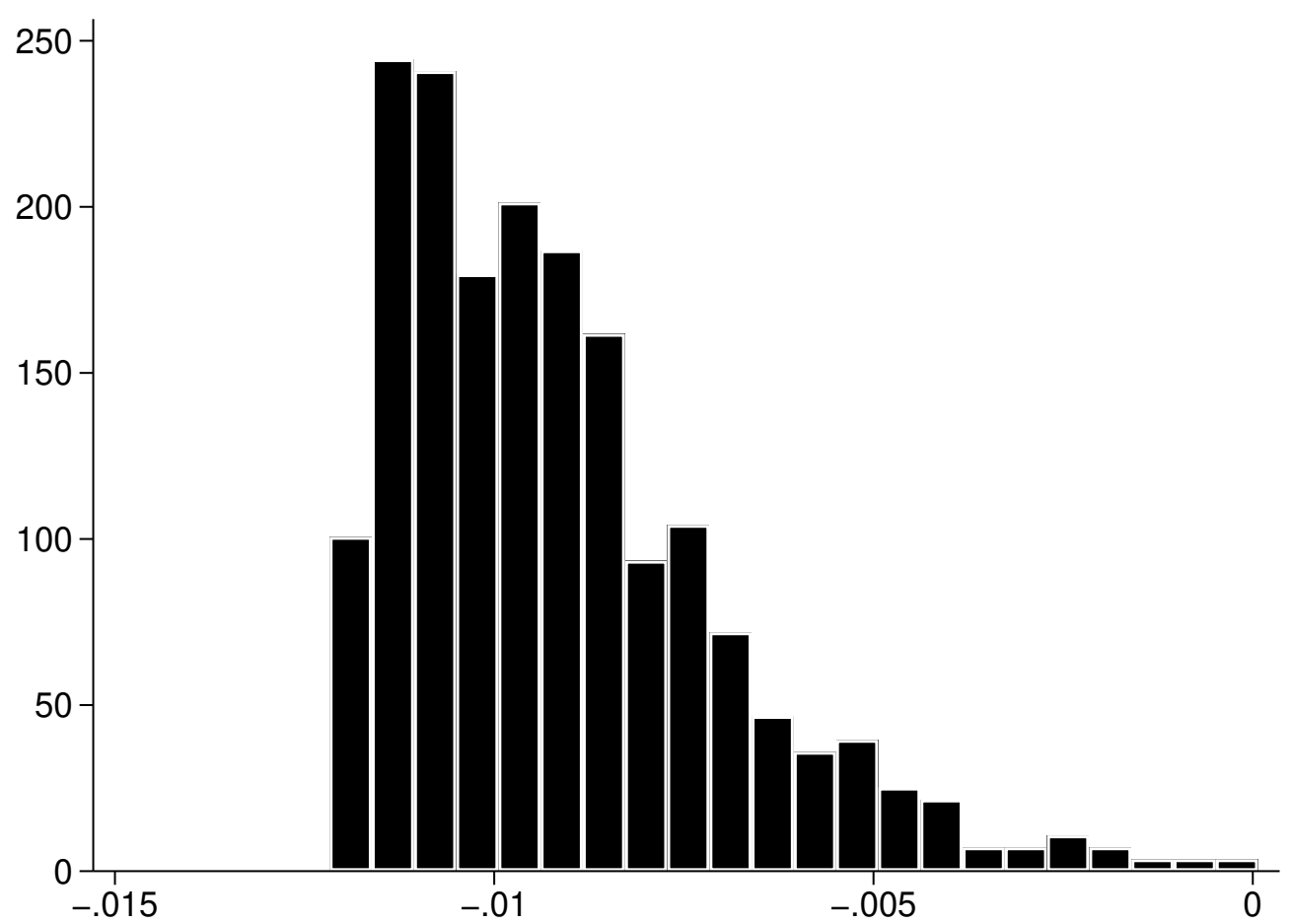

Figure 3: Frequency distribution of price sensitivity

Finally, the bottom panel of Table 2 displays the results of the pricing equation. We observe that improvements in 


\section{Table 3}

Product-level and segment-level price elasticities in the UK 2014Q1

\begin{tabular}{|c|c|c|c|c|c|}
\hline \multirow{3}{*}{ Store } & \multicolumn{3}{|c|}{ Product-level (average) } & \multirow{2}{*}{\multicolumn{2}{|c|}{$\begin{array}{c}\text { Segment-level } \\
\text { Cross-price elasticities }\end{array}$}} \\
\hline & \multirow[t]{2}{*}{ Own-price elasticities } & \multicolumn{2}{|c|}{ Cross-price elasticities } & & \\
\hline & & Same segment & Different segment & Same segment & Different segment \\
\hline \multicolumn{6}{|l|}{ Nested logit } \\
\hline Apple & -1.080 & 0.007 & 0.002 & 0.170 & 0.038 \\
\hline Android & -0.553 & $4 \mathrm{E}-04$ & $1 \mathrm{E}-04$ & 0.095 & 0.032 \\
\hline \multicolumn{6}{|c|}{ Nested Logit ${ }^{e}$} \\
\hline Apple & -0.959 & 0.005 & 0.014 & 0.131 & 0.035 \\
\hline Android & -0.491 & $3 \mathrm{E}-04$ & $1 \mathrm{E}-04$ & 0.075 & 0.029 \\
\hline \multicolumn{6}{|c|}{ RC nested logit } \\
\hline Apple & -7.854 & 0.224 & 0.005 & 5.605 & 0.1238 \\
\hline Android & -4.897 & 0.014 & $3 \mathrm{E}-04$ & 3.384 & 0.0952 \\
\hline \multicolumn{6}{|c|}{$\mathrm{RC}$ nested logit ${ }^{e}$} \\
\hline Apple & -8.487 & 0.242 & 0.006 & 6.044 & 0.148 \\
\hline Android & -5.394 & 0.015 & $5 E-04$ & 3.717 & 0.121 \\
\hline
\end{tabular}

Notes: ${ }^{e} \mathrm{RCNL}$ model with endogenous application quality.

tablet characteristics like higher storage, refined screen resolution, and larger screen size positively affect the marginal cost of producing and distributing tablets. For instance, to produce a tablet with an inch larger screen size, the marginal cost would increase by $\exp (0.113)-1=0.1196$ or $11.96 \%$.

We document the own-price elasticities, and cross-price elasticities averaged over products and segments in Table 3. We separate the cross-price elasticities into cross-price elasticities of products in the same segment and of products in other segments. The average own-price elasticities of Apple's products using iOS is, in absolute value, higher than that of Android-based tablets, but so is the average elasticity of products belonging to the same segment. These results have several implications for competition in the tablet market. As expected, competition between products within the same segment is more intense than that of products across segments. This is the result of a significant grouping parameter. This result tells us that products are differentiated across stores. Furthermore, business stealing is stronger within the iOS than within the Android operating system; implying that iPads are more homogeneous than Androidbased tablets. Finally, a price increase will lead to a larger loss of market shares of Apple products than Android-based tablets, due to the stronger business stealing effect in the iOS group.

Segment-level cross-price elasticities are reported in the last pair of columns. They show the average percentage change in the market share of a product in the nest if the prices of all products in that nest (same group) or other nests (different groups) increase by 1\%. It is not surprising that the cross-price elasticities are small between different segments, as the market has not tipped towards either of the two platforms. 


\subsection{Counterfactual analysis}

We run two counterfactual analyses. In the first one, we study what would have happened to the demands for tablets, prices, profits, and consumer surplus if the platforms had chosen to remove the low-quality apps to increase the average quality of the apps in their stores. In a second counterfactual, we show what would again have been the effect on the demands for tablets, prices, profits, and consumer surplus if a regulator would impose interoperability of apps between the two platforms.

\subsubsection{Counterfactual 1: Increasing apps quality by removing of low-quality apps}

In the above section, we have shown that the quality of mobile applications available in the app stores has a positive effect on the demand for tablets. To gain a better insight into its impact, we perform a counterfactual experiment aimed at studying what would be the effect on the demands for tablets, prices, and profits of tablet manufacturers of a decision to remove low-quality applications from the stores. The average application quality for each OS and country when all apps are included, and when the bottom 100 are excluded, is presented in Table A.3. We run such an experiment in each of the five country-based tablet markets, relying on our estimates of the random coefficient nested logit model with application quality treated as endogenous. We restrict the counterfactual to the last period, which is the first quarter of 2014.

Specifically, we study for each online store the removal of the $10 \%$ of the applications with the lowest quality. By doing so, the platform can improve the average quality of the apps available on its store, a fact that would positively impact the demand for tablets. From the tablet joint estimations, we back out the marginal costs with this counterfactual. We compute the new markups to calculate the new equilibrium prices and market shares by holding the marginal costs constant.

The results of this counterfactual, reported in Table 4, confirm Prediction 1. The increase in the average application rating produced by excluding the applications with the lowest quality in the platform has positive spillovers on the demand for tablets in that platform and on manufacturers' profits, and negative effects on the demand for tablets and profits of the manufacturers of the other platform. The absolute values of the own-effects are much larger than those of the cross-effects. This because competition between tablet producers across platforms is weak, as shown by the limited substitution patterns previously highlighted in Table 3. An increase in the average application quality in one store leads to a larger gain from the outside good than from demand from other competitors. The effects on prices are not significant. Furthermore, it is useful to compare the effects on tablet demands and profits of Apple and Android producers. The results of the K-Smirnov test confirm that the effects are always larger for Apple. This may be one of the reasons why Apple was the first to raise the quality standard of the applications published in its store in 2016 by imposing stricter guidelines for approving applications written by developers. This strategy has to lead to an increase 


\section{Table 4}

Counterfactual 1 -Removing $10 \%$ of apps with lowest rating

\begin{tabular}{|c|c|c|c|c|c|c|}
\hline & & France & Germany & Italy & Spain & UK \\
\hline \multicolumn{7}{|c|}{ Average own-effect } \\
\hline \multirow[t]{6}{*}{ Apple } & Price changes (\%) & $0.097 * *(\mathrm{R})$ & $-0.110 * *(\mathrm{R})$ & $0.003(F)$ & $-0.323(F)$ & $0.066(\mathrm{~F})$ \\
\hline & & $(0.001)$ & $(0.023)$ & $(0.002)$ & $(0.233)$ & $(0.077)$ \\
\hline & Market share changes (\%) & $12.190 * *(\mathrm{R})$ & $7.495 * *(\mathrm{R})$ & $7.475^{* *}(\mathrm{R})$ & $8.737^{* *}(\mathrm{R})$ & $6.650 * *(\mathrm{R})$ \\
\hline & & $(0.083)$ & $(0.148)$ & $(0.064)$ & $(0.541)$ & $(0.327)$ \\
\hline & Profit changes (\%) & $12.539 * *(\mathrm{R})$ & $7.225^{* *}(\mathrm{R})$ & $7.483 * *(\mathrm{R})$ & $7.941^{* *}(\mathrm{R})$ & $6.808 * *(\mathrm{R})$ \\
\hline & & $(0.074)$ & $(0.128)$ & $(0.065)$ & $(0.041)$ & $(0.378)$ \\
\hline \multirow[t]{5}{*}{ Android } & Price changes $(\%)$ & $-6.8 \mathrm{E}-04 * *$ & $-0.023 * *$ & $-0.009 * *$ & $-3 E-04$ & $-0.016 * *$ \\
\hline & & $(2.5 \mathrm{E}-04)$ & $(0.002)$ & $(0.001)$ & $(0.005)$ & $(0.005)$ \\
\hline & Market share changes (\%) & $3.542 * *$ & $3.462 * *$ & $2.909 * *$ & $2.010 * *$ & $3.801 * *$ \\
\hline & & $(0.008)$ & $(0.015)$ & $(0.009)$ & $(0.019)$ & $(0.031)$ \\
\hline & Profit changes $(\%)$ & $\begin{array}{l}3.534 * * \\
(0.008)\end{array}$ & $\begin{array}{l}3.363^{* *} \\
(0.016)\end{array}$ & $\begin{array}{l}2.863^{* *} \\
(0.012)\end{array}$ & $\begin{array}{l}1.992 * * \\
(0.009)\end{array}$ & $\begin{array}{l}3.650 * * \\
(0.042)\end{array}$ \\
\hline
\end{tabular}

\begin{tabular}{|c|c|c|c|c|c|c|}
\hline \multicolumn{7}{|c|}{ Average cross-effect } \\
\hline \multirow[t]{6}{*}{ Apple } & Price changes $(\%)$ & $-0.022 * *(\mathrm{R})$ & $-0.241 * *(\mathrm{R})$ & $-0.061 * *(\mathrm{R})$ & $-0.332(F)$ & $-0.048(F)$ \\
\hline & & $(4.8 \mathrm{E}-04)$ & $(0.026)$ & $(0.018)$ & $(0.210)$ & $(0.037)$ \\
\hline & Market share changes (\%) & $-0.323 * *(\mathrm{R})$ & $0.059(\mathrm{R})$ & $-0.157 * *(\mathrm{R})$ & $-0.157 * *(\mathrm{R})$ & $-0.551 *(\mathrm{R})$ \\
\hline & & $(0.019)$ & $(0.163)$ & $(0.009)$ & $(0.016)$ & $(0.245)$ \\
\hline & Profit changes (\%) & $-0.397 * *(\mathrm{R})$ & $-0.462 * *(\mathrm{R})$ & $-0.325 * *(\mathrm{R})$ & $0.104(\mathrm{R})$ & $-0.674 * *(\mathrm{R})$ \\
\hline & & $(0.020)$ & $(0.093)$ & $(0.020)$ & $(0.353)$ & $(0.016)$ \\
\hline \multirow[t]{6}{*}{ Android } & Price changes $(\%)$ & $-0.015^{* *}$ & $-0.126 * *$ & $-0.031 * *$ & -0.018 & $-0.060 * *$ \\
\hline & & $(7.4 \mathrm{E}-04)$ & $(0.015)$ & $(0.003)$ & $(0.018)$ & $(0.014)$ \\
\hline & Market share changes (\%) & $-0.383^{* *}$ & $-0.533 * *$ & $-0.242 * *$ & $-0.280 * *$ & $-0.676 * *$ \\
\hline & & $(0.015)$ & $(0.063)$ & $(0.018)$ & $(0.061)$ & $(0.083)$ \\
\hline & Profit changes (\%) & $-0.466 * *$ & $-1.016 * *$ & $-0.386 * *$ & $-0.380 * *$ & $-0.901 * *$ \\
\hline & & $(0.018)$ & $(0.054)$ & $(0.022)$ & $(0.027)$ & $(0.048)$ \\
\hline \multicolumn{7}{|c|}{ Consumer welfare effect $(\%)$} \\
\hline Apple & & 3.098 & 3.223 & 2.000 & 2.132 & 2.329 \\
\hline Android & & 2.673 & 1.840 & 2.094 & 1.441 & 0.925 \\
\hline
\end{tabular}

in worldwide market shares of Apple's iPad, as shown in Table A.4. One year later, Google followed this strategy by imposing stricter control for applications, which led to the removal of many low-quality apps. 


\section{Table 5}

Counterfactual 2- Compulsory interoperability of apps

\begin{tabular}{|c|c|c|c|c|c|c|}
\hline & & France & Germany & Italy & Spain & UK \\
\hline \multirow[t]{6}{*}{ Apple } & Price changes (\%) & $-0.008 * *$ & $-0.072 * *$ & $-0.090 * *$ & $-0.552 *$ & $-0.085 * *$ \\
\hline & & $(1 \mathrm{E}-04)$ & $(0.009)$ & $(0.006)$ & $(0.272)$ & $(0.045)$ \\
\hline & Market share changes (\%) & $-0.613^{* *}$ & -1.199 & $-4.273 * *$ & $-5.068 * *$ & $-3.863 * *$ \\
\hline & & $(6 \mathrm{E}-04)$ & $(0.085)$ & $(0.026)$ & $(1.078)$ & $(0.048)$ \\
\hline & Profit changes $(\%)$ & $-0.635 * *$ & $-1.352^{* *}$ & $-4.492 * *$ & $-6.237 * *$ & $-4.053 * *$ \\
\hline & & $(3 E-04)$ & $(0.035)$ & $(0.011)$ & $(0.465)$ & $(0.182)$ \\
\hline \multirow[t]{5}{*}{ Android } & Price changes (\%) & $6 \mathrm{E}-04 * *$ & $0.013^{* *}$ & $0.004^{* *}$ & -0.006 & $0.020 * *$ \\
\hline & & $(0.000)$ & $(0.001)$ & $(0.001)$ & $(0.006)$ & $(0.004)$ \\
\hline & Market share changes (\%) & $0.582^{* *}$ & $1.353^{* *}$ & $4.306^{* *}$ & $6.576^{* *}$ & $4.162^{* *}$ \\
\hline & & $(7 \mathrm{E}-04)$ & $(0.007)$ & $(0.007)$ & $(0.019)$ & $(0.047)$ \\
\hline & Profit changes (\%) & $\begin{array}{l}0.585 * * \\
(0.002)\end{array}$ & $\begin{array}{l}1.399 * * \\
(0.010)\end{array}$ & $\begin{array}{l}4.320 * * \\
(0.004)\end{array}$ & $\begin{array}{l}6.551 * * \\
(0.010)\end{array}$ & $\begin{array}{l}4.232 * * \\
(0.010)\end{array}$ \\
\hline \multicolumn{7}{|c|}{ Consumer welfare effect $(\%)$} \\
\hline & & 0.283 & 0.147 & 1.922 & 2.830 & -0.235 \\
\hline
\end{tabular}

\subsubsection{Counterfactual 2: Compulsory interoperability of apps}

In this counterfactual, we aim to study the effects of a possible policy intervention by a regulator imposing all applications to be the same in both stores. As explained above, this can be seen as a proxy for mandating interoperability between the two platforms. To implement this counterfactual, we impose that the average quality of the apps is the same in the two stores and equal to the maximum quality between the two stores. As explained above, this is a natural way to implement interoperability in our setting as users in the store with higher average app quality will not be affected, while users in the store with lower average quality can benefit from higher quality apps.

Similar to the first counterfactual, also in this case we restrict ourselves to the last period, which is the first quarter of 2014; as shown Table A.3 in Appendix A.3, in this period the average application quality in Apple Store is higher than in Google Play in all the countries. Hence, imposing interoperability implies an increase in the average quality of the apps for Android tablets.

Our results support the second prediction of our theoretical model. The market shares of Android products go up, while those of iPads go down. This is clearly due to the fact that imposing interoperability translates into an increase in the average quality of the apps available for Android tablets while that for Apple tablets stays unchanged, leading to a shift in demand from Apple to Android tablets. Interestingly, at least for Spain, the UK, and Italy, the decrease in Apple market share is more than compensated by the increase in Android market share. Also this finding is in line with our theoretical prediction and reveals that a policy that mandates platforms interoperability promotes the adoption of 
tablet technologies.

The results on profits suggest that Android tablet producers gain from interoperability, while Apple loses and may want to fight to prevent this from happening. As predicted, the effect on prices is asymmetric. Apple is willing to reduce its prices to protect its demand (and profits), whereas Android tablet producer prices do not change by much. Finally, our prediction in terms of the effect on consumer welfare is also confirmed; the counterfactual results suggest in fact that on the market for tablets, interoperability across platforms increases consumer welfare.

\section{Conclusions}

This paper examines the role of quality of applications on the tablet demand, focusing on the case of iOS versus Android. Moving from a simple theoretical model of duopolistic competition in the tablet market, we empirically evaluate the theoretical predictions that emerge from the model. We combine tablet and app data across 5 European countries over the quarters 2013Q3-2014Q1 to estimate the demand and pricing equations for tablets, jointly. Our results provide evidence of the relevance of application quality on the market for tablets. An increase in application quality raises the demand for tablets.

The magnitudes of these effects differ between platforms, with the effect of iPads being larger than for Androidbased tablets. To study the importance of these effects on the tablet market, we perform a sequence of counterfactual experiments. First, we separately let each application store remove $10 \%$ of the lowest quality applications and compute the new equilibrium market shares, prices, and profits of tablet producers. The results show that the total profit of Apple increases proportionally more significantly than for Android tablet manufacturers. If there was no significant loss in profits coming from the application markets (which would be the case if low-quality applications generate a marginal profit), our result could be seen as evidence that Apple has an incentive to improve its application quality, for instance, by imposing higher quality standards to the developers. Another interesting exercise that we conduct is to study the effect of a regulator imposing the interoperability of mobile applications. When we impose all applications to be the same in both stores, we find that redistribution of application quality plays a key role. Before the counterfactual, Apple has larger application quality in all markets. Interoperability implies that while the average quality of apps for Apple tablets is unchanged, that of Android onse clearly increases. The effect of this rearrangement is that Android tablet producers would gain more market shares and profits from interoperability at the expense of Apple. Interestingly, this policy has a negative and significant impact on Apple product prices, but negligible effects on Android tablet prices. If the regulator cares only about consumer welfare, then this restriction should go ahead as it would enhance consumer surplus.

The paper has several limitations, which can be extended in several ways. In the first place, because of the lack of data, we cannot use variety (number) of applications as a source of indirect quality, as done in previous literature. 
Nonetheless, since the number of applications available is enormous (over 2 million), it is legitimate to believe that consumers value application quality more than variety. A valuable extension of this paper is modelling the effect of quality and estimating the effects of application quality on the tablet market and tablet quality on the application market jointly. Lack of enough periods of data has prevented us from doing so. Similarly, it is interesting to unravel the role of application quality in the developer's decision to publish paid or free applications. Another point that deserves investigation is the possibility of self-selection in app-rating by store by using the information on multihomed apps. In this case, app in different stores may suggest different types of users, with different benchmark values of what is high and low quality, with implications on the reviews for the same product. 


\section{The effect of application quality}

\section{References}

Steven Berry, James Levinsohn, and Ariel Pakes. Automobile prices in market equilibrium. Econometrica: Journal of the Econometric Society, pages 841-890, 1995.

Steven T. Berry. Estimating discrete-choice models of product differentiation. The RAND Journal of Economics, 25(2):242-262, 1994.

Steven T. Berry and Philip A. Haile. Identification in differentiated products markets using market level data. Econometrica, 82(5):1749-1797, 2014.

N. Scott Cardell. Variance components structures for the extreme-value and logistic distributions with application to models of heterogeneity. Econometric Theory, 13(2):185-213, 1997.

Ramon Casadesus-Masanell and Hanna Hałaburda. When does a platform create value by limiting choice? Journal of Economics \& Management Strategy, 23(2):259-293, 2014.

Jeffrey Church and Neil Gandal. Complementary network externalities and technological adoption. International Journal of Industrial Organization, 11:239-260, 1992.

Stefano Comino, Fabio M. Manenti, and Franco Mariuzzo. Updates management in mobile applications. itunes vs google play. Journal of Economics and Management Strategy, 28(3):392-419, 2018.

Kenneth S. Corts and Mara Lederman. Software exclusivity and the scope of indirect network effects in the u.s. home video game market. International Journal of Industrial Organization, 27:121-136, 2009.

Nicholas Economides. Desirability of compatibility in the absence of network externalities. The Review of Economics and Statistics, 79(5):11651181, 1989.

Joseph Farrell and Garth Saloner. Standardization, compatibility, and innovation. RAND Journal of Economics, 16(1):70-83, 1985.

Laura Grigolon and Frank Verboven. Nested logit or random coefficients logit? a comparison of alternative discrete choice models of product differentiation. The Review of Economics and Statistics, 96(5):916-935, 2014.

Andrei Hagiu. Quantity vs. quality and exclusion by two-sided platforms. Harvard Business School Strategy Unit Working Paper, 2009.

Jerry Hausman and William Taylor. Panel data and unobservable individual effects. Econometrica, 49(6):1377-1398, 1981.

Michael L. Katz and Carl Shapiro. Network externalities, competition, and compatibility. American Economic Reviews, 75(3):424-440, 1985.

Michael L. Katz and Carl Shapiro. Technology adoption in the presence of network externalities. Journal of Political Economy, 94(4):822-841, 1986.

Michael L. Katz and Carl Shapiro. Systems competition and network effects. Journal of Economics Perspective, 8(2):93-115, 1994.

Jin-Hyuk Kim, Jeffrey Prince, and Calvin Qiu. Indirect network effects and the quality dimension: A look at the gaming industry. International Journal of Industrial Organization, 37:99-108, 2014.

Charles J. Stone Leo Breiman, Jerome Friedman and R.A. Olshen. Classification and Regression Trees. Wadsworth, Belmont CA, 1984.

Carmen Matutes and Pierre Regibeau. "mix and match": Product compatibility without network externalities. The RAND Journal of Economics, 19(2):221-234, 1988.

Daniel McFadden. Modelling the choice of residential location. In A. Karlqvist, L. Lundqvist, F. Snickars, and J. Weibull, editors, Spatial interaction theory and planning models, pages 75-96. North Holland, Armsterdam, 1978.

Harikesh Nair, Pradeep Chintagunta, and Jean-Pierre Dubé. Empirical analysis of indirect network effects in the market for personal digital assistants. Quantitative Marketing and Economics, 2(1):23-58, 2004.

Aviv Nevo. Measuring market power in the ready-to-eat cereal industry. Econometrica, 69(2):307-342, 2001.

María Fernanda Viecens. Two-sided platforms with endogenous quality differentiation. Universidad Carlos III de Madrid working paper, 2006. 


\section{A. Appendix}

\section{A.1. The equilibrium of the theoretical model}

The indifferent customer is identified by:

$$
\tilde{x}_{12}=\frac{l_{1}+l_{2}}{2}-\frac{p_{h 1}-p_{h 2}+z_{h 1} \bar{z}_{s 1}-z_{h 2} \bar{z}_{s 2}}{2 k} .
$$

Customers to the left of $l_{1} /$ resp. to the right of $l_{2}$, have to decide whether to adopt platform 1/resp. platform 2, or not to adopt any platform. They adopt if they receive a non-negative net utility; formally, the indifferent customer between adopting platform 1/resp. platform 2 or not adopting are located in: ${ }^{11}$

$$
\tilde{x}_{10}=l_{1}+\frac{z_{h 1} \bar{z}_{s 1}-p_{h 1}}{k}, \quad \text { and } \quad \tilde{x}_{20}=l_{2}+\frac{z_{h 2} \bar{z}_{s 2}-p_{h 2}}{k} .
$$

Consumers located between $\tilde{x}_{10}$ and $\tilde{x}_{12}$ join platform 1 while those located between $\tilde{x}_{12}$ and $\tilde{x}_{20}$ join platform $2 ;^{12}$ the total demand for platform 1 is therefore $q_{h 1}=\tilde{x}_{12}-\tilde{x}_{10}$, while that for platform 2 is $q_{h 2}=\tilde{x}_{20}-\tilde{x}_{12}$. Using expressions (18) and (19), we can rewrite these demands as follows:

$$
\begin{aligned}
& q_{h 1}\left(p_{h 1}, p_{h 2}\right)=\frac{l_{2}-l_{1}}{2}+\frac{3 z_{h 1} \bar{z}_{s 1}-z_{h 2} \bar{z}_{s 2}-\left(3 p_{h 1}-p_{h 2}\right)}{2 k} \\
& q_{h 2}\left(p_{h 1}, p_{h 2}\right)=\frac{l_{2}-l_{1}}{2}+\frac{3 z_{h 2} \bar{z}_{s 2}-z_{h 1} \bar{z}_{s 1}+\left(p_{h 1}-3 p_{h 2}\right)}{2 k} .
\end{aligned}
$$

The profit function of the producer of the tablet in platform 1 given $p_{h 1}$ and $p_{h 2}$ is therefore:

$$
\pi_{h 1}\left(p_{h 1}, p_{h 2}\right)=\left(p_{h 1}-c_{1}\right)\left(\frac{l_{2}-l_{1}}{2}+\frac{3 \bar{z}_{s 1} z_{h 1}-\bar{z}_{s 2} z_{h 2}-\left(3 p_{h 1}-p_{h 2}\right)}{2 k}\right),
$$

where $c_{1}$ is the firm marginal cost of production.

For later purposes, it is also useful to report the first stage overall profits $\Pi_{h 2}=\sum_{n} \pi_{h 2, i}$, enjoyed by the tablet manufacturers in platform 2, given prices:

$$
\Pi_{h 1}\left(p_{h 1}, p_{h 2}\right)=\left(p_{h 2}-c_{2}\right)\left(\frac{l_{2}-l_{1}}{2}+\frac{3 \bar{z}_{s 2} z_{h 2}-\bar{z}_{s 1} z_{h 1}+\left(p_{h 1}-3 p_{h 2}\right)}{2 k}\right) .
$$

Solving the first order condition, and given that the price of platform 2 tablets is as in expression (1), it is possible

\footnotetext{
${ }^{11}$ Under very mild conditions on model parameters, it is possible to show that at the equilibrium these marginal customers, and therefore also the non marginal ones, do not find optimal to purchase from the distant firm. Proof is available upon request from the authors.

${ }^{12}$ All through this section, we assume that at the equilibrium the model admits an internal solution: $0<\tilde{x}_{10}<\tilde{x}_{12}<\tilde{x}_{20}<1$.
} 
to derive the equilibrium price of platform 1 tablets, given software and hardware qualities: ${ }^{13}$

$$
p_{h 1}^{*}=\frac{3 c_{1}+c_{2}}{6}+\frac{t+n\left(3 \bar{z}_{s 1} z_{h 1}-\bar{z}_{s 2} z_{h 2}\right)+k n\left(l_{2}-l_{1}\right)}{6 n} .
$$

Using $p_{h 1}^{*}$ and $p_{h 2}^{*}$, equilibrium quantities, given expectations on the average quality of the apps available in the two platforms, are the following:

$$
q_{h 1}^{*}=\frac{l_{2}-l_{1}}{4}+\frac{1}{4} \frac{t}{k n}+\frac{3 \bar{z}_{s 1} z_{h 1}-\bar{z}_{s 2} z_{h 2}-3 c_{1}+c_{2}}{4 k},
$$

and

$$
q_{h 2}^{*}=\frac{7\left(l_{2}-l_{1}\right)}{12}-\frac{17}{12} \frac{t}{k n}-\frac{3 \bar{z}_{s 1} z_{h 1}-17 \bar{z}_{s 2} z_{h 2}-3 c_{1}+17 c_{2}}{4 k} .
$$

\section{A.2. Robustness checks}

\section{A.2.1. Different measure of application quality}

The average rating of users of an application is believed to represent a trustworthy measure of how good the application is, and influence as such the downloading of that application by users.

Figure A.1 shows that both the weighted average and the median ratings of top ranked 100 apps are substantially higher than for applications ranked 901st-1000th in the UK App Store; this because users tend to prefer applications with higher ratings, as these ratings signal quality.

We carry out a sequence of robustness regressions to check whether our results based on an overall weighted average quality of applications are consistent with different measures of app ratings. We re-estimate the RCNL model documented in the last pair of columns of table 2 base on the measures of quality: weighted average ratings of top 100 apps in the store, weighted average ratings of top 200 apps in the store, the weighted average rating of apps ranked 9011000 , the weighted average rating of apps ranked 801-1000 and the median rating of top 1000 apps. The robustness check results are reported in table A.1. When application quality is proxied by the median, the result of the app quality coefficient is the largest. Whereas, the results when using weighted average of top 100 applications and top 200 apps are very similar, with both being positive and significant. In contrast, the estimated coefficients when application quality measure by apps ranked 901-1000, apps ranked 801-1000 are not statistically significant. Intuitively, these results reveal the fact that the top apps dominate the effect of app quality in the tablets market. Thus, we should put more weight on these apps, and thus the weighted average rating is a preferred measure of application quality.

\footnotetext{
${ }^{13}$ It is easy to check that the second order condition is satisfied.
} 


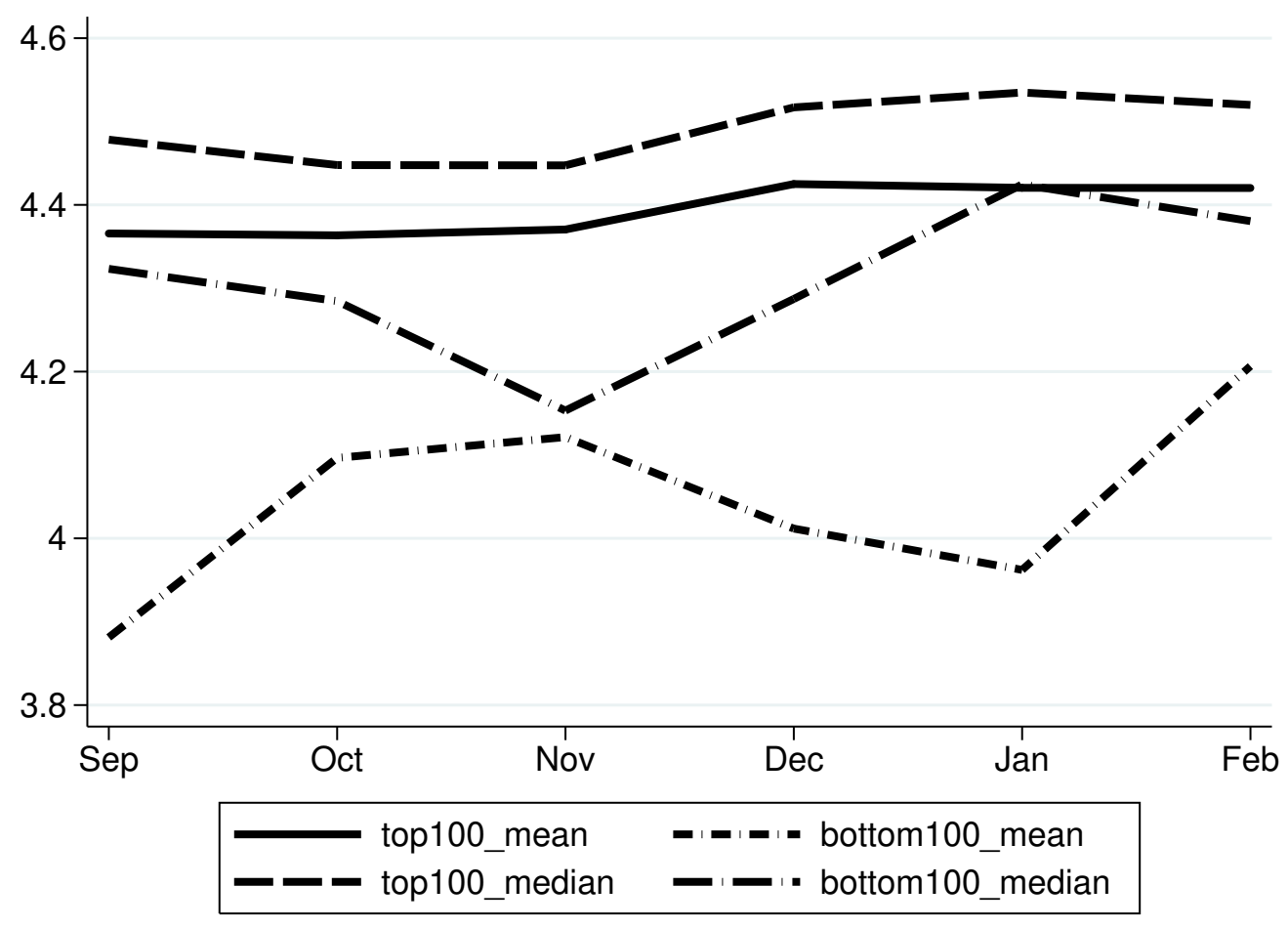

Figure A.1: Weighted average and median application rating of top and bottom 100 applications of the 1000 most downloaded applications in the UK App Store during the period 2013M09-2014M02

\section{A.3. Additional tables}


Table A.1

Different measures of application quality

\begin{tabular}{|c|c|c|c|c|c|c|c|c|c|c|}
\hline & \multicolumn{2}{|c|}{ Top 100} & \multicolumn{2}{|c|}{ Top 200} & \multicolumn{2}{|c|}{ Apps 901-1000 } & \multicolumn{2}{|c|}{ Apps $801-1000$} & \multicolumn{2}{|c|}{ Median } \\
\hline & $\begin{array}{c}\text { Parameter } \\
\text { (1) }\end{array}$ & $\begin{array}{l}\text { SE } \\
(1)\end{array}$ & $\begin{array}{c}\text { Parameter } \\
\text { (2) }\end{array}$ & $\begin{array}{l}\text { SE } \\
(2)\end{array}$ & $\begin{array}{c}\text { Parameter } \\
\text { (3) }\end{array}$ & $\begin{array}{l}\text { SE } \\
(3)\end{array}$ & $\begin{array}{c}\text { Parameter } \\
\text { (4) }\end{array}$ & $\begin{array}{l}\text { SE } \\
(4)\end{array}$ & $\begin{array}{c}\text { Parameter } \\
\text { (5) }\end{array}$ & $\begin{array}{l}\text { SE } \\
(5)\end{array}$ \\
\hline \multicolumn{11}{|c|}{ Demand side } \\
\hline Constant & $-16.165 * *$ & 0.031 & $-15.914 * *$ & 0.035 & $-15.117^{* *}$ & 3.329 & $-15.738 * *$ & 3.081 & $-16.587^{* *}$ & 0.275 \\
\hline Storage & $0.005 * *$ & 0.001 & $0.004 *$ & 0.002 & -0.004 & -0.005 & 0.003 & 0.001 & 0.003 & 0.004 \\
\hline Screen resolution & $0.610 * *$ & 0.044 & $0.583 * *$ & 0.065 & $0.475^{* *}$ & 0.159 & $0.447 * *$ & 0.049 & $0.483^{* *}$ & 0.116 \\
\hline Screen size & $0.103 * *$ & 0.016 & $0.094 * *$ & 0.026 & 0.037 & 0.043 & 0.037 & 0.024 & $0.076 * *$ & 0.027 \\
\hline Connection & $0.285^{* *}$ & 0.042 & $0.265^{* *}$ & 0.071 & 0.065 & 0.127 & 0.052 & 0.075 & $0.207 *$ & 0.10 \\
\hline Application quality & $0.952 * *$ & 0.130 & $0.980 * *$ & 0.175 & 0.932 & 0.874 & 1.167 & 0.678 & $1.417^{* *}$ & 0.410 \\
\hline Price $\left(\beta_{\mathrm{p}}\right)$ & $-0.010 * *$ & 4E-04 & $-0.009 * *$ & 0.001 & $-0.007^{* *}$ & 0.002 & $-0.007 * *$ & 0.001 & $-0.008 * *$ & 0.001 \\
\hline Price $\left(\sigma_{\mathrm{p}}\right)$ & $0.007 * *$ & 0.001 & $0.007 * *$ & 0.003 & 0.005 & 0.058 & 0.005 & 0.022 & 0.005 & 0.018 \\
\hline Price $\left(\pi_{\mathrm{p}}\right)$ & $0.014 * *$ & $6 \mathrm{E}-04$ & $0.013 * *$ & 0.001 & $0.012 *$ & 0.006 & $0.013^{* *}$ & 0.002 & $0.011^{* *}$ & 0.004 \\
\hline Correlation $\rho$ & $0.657^{* *}$ & 0.014 & $0.665^{* *}$ & 0.025 & $0.524 * *$ & 0.102 & $0.522 * *$ & 0.078 & $0.670 * *$ & 0.083 \\
\hline \multicolumn{11}{|c|}{ Pricing equation } \\
\hline Constant & $0.318 * *$ & 0.066 & 0.219 & 0.828 & 0.536 & 24.524 & 1.118 & 2.466 & 0.639 & 5.532 \\
\hline Storage & 0.004 & 0.003 & 0.004 & 0.010 & $-4 E-04$ & 0.053 & -0.001 & 0.033 & 0.004 & 0.006 \\
\hline Screen resolution & $0.247 * *$ & 0.013 & $0.251^{* *}$ & 0.042 & 0.156 & 1.902 & 0.116 & 0.346 & 0.216 & 0.427 \\
\hline Screen size & $0.121 * *$ & 0.024 & $0.123 * *$ & 0.030 & 0.204 & 0.308 & 0.202 & 0.799 & $0.128 * *$ & 0.026 \\
\hline Connection & $0.269 * *$ & 0.062 & $0.277^{*}$ & 0.112 & 0.317 & 1.971 & 0.306 & 3.420 & 0.285 & 0.211 \\
\hline \multicolumn{11}{|c|}{ Model Statistics } \\
\hline $\mathrm{N}$ & \multicolumn{2}{|c|}{3753} & \multicolumn{2}{|c|}{3753} & \multicolumn{2}{|c|}{3753} & \multicolumn{2}{|c|}{3753} & \multicolumn{2}{|c|}{3753} \\
\hline Pseudo $\mathrm{R}_{D}^{2}$ & \multicolumn{2}{|c|}{0.675} & \multicolumn{2}{|c|}{0.666} & \multicolumn{2}{|c|}{0.596} & \multicolumn{2}{|c|}{0.616} & \multicolumn{2}{|c|}{0.678} \\
\hline Pseudo $\mathrm{R}_{S}^{2}$ & \multicolumn{2}{|c|}{0.649} & \multicolumn{2}{|c|}{0.654} & \multicolumn{2}{|c|}{0.416} & \multicolumn{2}{|c|}{0.381} & \multicolumn{2}{|c|}{0.632} \\
\hline J-stat & \multicolumn{2}{|c|}{16.823} & \multicolumn{2}{|c|}{17.051} & \multicolumn{2}{|c|}{13.541} & \multicolumn{2}{|c|}{27.895} & \multicolumn{2}{|c|}{20.413} \\
\hline $\mathrm{N} \mathrm{mc}<0$ & \multirow{2}{*}{\multicolumn{2}{|c|}{$\begin{array}{c}10 \\
0.280\end{array}$}} & \multirow{2}{*}{\multicolumn{2}{|c|}{$\begin{array}{c}10 \\
0.292\end{array}$}} & \multicolumn{2}{|c|}{142} & 16 & & 11 & \\
\hline Average price-cost margin & & & & & 0.5 & & 0.5 & & 0.3 & \\
\hline
\end{tabular}

Notes: The table presents the results of the random coefficients nested logit estimation when we use different measures for application quality. Significance level: $* p<0.05, * * p<0.01$. e: Application quality is treated as endogenous. Time, country and firm fixed effects are included both in the demand and pricing equations but not reported. Instruments: $h_{1}, h_{2}, h_{4}, h_{6}, h_{7}, h_{8}$.

Table A.2

Instrument strength of demand side-First stage regression results

\begin{tabular}{lrrrrrr}
\hline \multirow{2}{*}{ Variables } & \multicolumn{2}{c}{ Price } & \multicolumn{2}{c}{ Ln(sjg) } & Application quality \\
\cline { 2 - 6 } & Parameters & \multicolumn{1}{c}{ SE } & Parameters & SE \\
\hline Cons & $-1349.835^{* *}$ & 182.425 & $-8.780^{* *}$ & 4.865 & $5.204^{* *}$ & 0.108 \\
Storage & $2.058^{* *}$ & 0.066 & $-0.026 * *$ & 0.000 & $-4 \mathrm{E}-05$ & $3 \mathrm{E}-05$ \\
Screenres & $82.808^{* *}$ & 2.247 & $0.306^{* *}$ & 0.060 & $4 \mathrm{E}-04$ & 0.001 \\
Screensize & $16.915^{* *}$ & 0.857 & $-0.151^{* *}$ & 0.023 & $-5 \mathrm{E}-05$ & 0.001 \\
Connectivity & $62.854^{* *}$ & 2.155 & $-0.464^{* *}$ & 0.057 & 0.001 & 0.001 \\
$h_{1}$ & -0.152 & $0.135 *$ & $0.003 *$ & 0.001 & $2 \mathrm{E}-05$ & $3 \mathrm{E}-05$ \\
$h_{2}$ & $0.624^{* *}$ & 0.042 & $-0.005^{* *}$ & 0.001 & $7 \mathrm{E}-05^{* *}$ & $2 \mathrm{E}-05$ \\
$h_{3}$ & $0.035^{* *}$ & 0.015 & $-0.002^{* *}$ & 0.000 & $-4 \mathrm{E}-05^{* *}$ & $9 \mathrm{E}-06$ \\
$h_{4}$ & 19.677 & 18.726 & 0.182 & 0.499 & $-0.153^{* *}$ & 0.011 \\
$h_{6}$ & $-8.566 *$ & 3.937 & 0.070 & 0.105 & $0.019 * *$ & 0.002 \\
$h_{8}$ & $-6.128 *$ & 3.086 & 0.075 & 0.082 & $-2 \mathrm{E}-04$ & 0.002 \\
\hline
\end{tabular}

$\begin{array}{lccc}\text { Statistics } & & & \\ \mathrm{N} & 3753 & 3753 & 3753 \\ \text { F-stat instr } & 41.850 & 11.830 & 47.680 \\ \text { F p-val } & 0.000 & 0.000 & 0.000\end{array}$

Notes: The table presents the results of the first-stage IV GMM estimation with dependent variables price, log within the market share, and application quality (endogenous variables in the regression. Significance level: $* p<0.05, * * p<0.01$. Time, country and firm fixed effects are included but not reported. 
Table A.3

Changes in average app rating when excluding $10 \%$ of low quality apps and imposing interoperability

\begin{tabular}{llrrr|lllll}
\hline \multicolumn{3}{c}{ Exclusion of $10 \%$ low quality apps } & \multicolumn{5}{c}{ Interoperability } \\
\hline Country & OS & Top 1000 & Top 900 & Change & Country & OS & Before & After & Change \\
\hline France & iOS & 4.155 & 4.333 & 0.178 & France & iOS & 4.155 & 4.155 & 0.000 \\
& Android & 4.138 & 4.192 & 0.054 & & Android & 4.138 & 4.155 & 0.017 \\
Germany & iOS & 4.219 & 4.335 & 0.116 & Germany & iOS & 4.219 & 4.219 & 0.000 \\
& Android & 4.180 & 4.233 & 0.053 & & Android & 4.180 & 4.219 & 0.039 \\
Italy & iOS & 4.275 & 4.385 & 0.110 & Italy & iOS & 4.275 & 4.275 & 0.000 \\
& Android & 4.149 & 4.193 & 0.044 & & Android & 4.149 & 4.275 & 0.126 \\
Spain & iOS & 4.223 & 4.335 & 0.111 & Spain & iOS & 4.223 & 4.223 & 0.000 \\
& Android & 4.034 & 4.065 & 0.031 & & Android & 4.034 & 4.223 & 0.189 \\
UK & iOS & 4.266 & 4.380 & 0.114 & UK & iOS & 4.266 & 4.266 & 0.000 \\
& Android & 4.146 & 4.206 & 0.060 & & Android & 4.146 & 4.266 & 0.120 \\
\hline
\end{tabular}

Notes: The table presents the absolute changes in the average rating of both iOS and Android apps in the case where we exclude $10 \%$ of the lowest quality apps (apps with rating ranked between 901 and 1000) in the two stores, and the case where we impose interoperability across the two stores.

Table A.4

Global tablet PC market shares by OS

\begin{tabular}{clcc}
\hline Year & iOS & Android & Windows \\
\hline 2013 & 33.93 & 62.36 & 3.50 \\
2014 & 27.57 & 67.33 & 5.09 \\
2015 & 23.90 & 67.40 & 8.60 \\
2016 & 22.40 & 66.20 & 11.30 \\
2017 & 25.63 & 61.06 & 13.31 \\
2018 & 25.67 & 58.34 & 15.98 \\
2019 & 25.70 & 56.50 & 17.80 \\
\hline
\end{tabular}

Notes: The table shows the global market share of three OS from 20132019. Source: Statista (2019). 